\title{
A SAFE WAY OF PERFORMING DANGEROUS EXPERIMENTS. III. THE SAFETY BOX. \\ 2. DEMONSTRATING THE REACTIONS OF ALKALI METALS WITH CONCENTRATED OXOACIDS
}

\author{
Slavica Aleksova, Miha Bukleski", Vladimir M. Petruševski \\ Institute of Chemistry, Faculty of Natural Sciences and Mathematics, \\ Ss. Cyril and Methodius University, Arhimedova 5, PO Box 162, 1000 Skopje, Macedonia \\ mihabukleski@pmf.ukim.mk
}

\begin{abstract}
A way to control some of the most dangerous reactions and, at the same time, introduce a systematic approach toward the study of the reactions of the alkali metals with acids has been offered. Explanations of the observed phenomena, considering the vigorous nature of the reactions and the circumstances contributing to the rate of reaction due to the precipitate formation or the presence of water, are discussed. The reactions between some concentrated aqueous solutions of oxoacids $\left(\mathrm{HNO}_{3}\right.$, $\left.\mathrm{H}_{3} \mathrm{PO}_{4}, \mathrm{H}_{2} \mathrm{SO}_{4}, \mathrm{HClO}_{4}\right)$ and alkali metals ( $\mathrm{Li}, \mathrm{Na}, \mathrm{K}$ ) are considered. Video clips of the experiments were prepared as an aid for those instructors who lack experience and/or the necessary materials. This publication is a continuation of the previously published article about the reaction of alkali metals with hydrohalic acids and is part of the series of publications under the general title "A Safe Way of Performing Dangerous Experiments".
\end{abstract}

Keywords: dangerous experiments; safety box; alkali metals; oxoacids

\section{БЕЗБЕДЕН НАЧИН НА ИЗВЕДУВАЊЕ ОПАСНИ ЕКСПЕРИМЕНТИ.} III. БЕЗБЕДНОСНА КУТИЈА.

\section{2. ДЕМОНСТРАЦИИ НА РЕАКЦИИ НА АЛКАЛНИ МЕТАЛИ СО КОНЦЕНТРИРАНИ ОКСОКИСЕЛИНИ}

\begin{abstract}
Понуден е начин за контролирано изведување на едни од најопасните реакции и истовремено е даден систематски приод кон изучувањето на реакциите на алкалните метали со киселини. Дадени се објаснувањата за набљудуваните феномени во однос на бурноста на реакциите, како и условите кои придонесуваат за брзината на реакцијата, а се должат на образуваните талози или присуството на вода. Разгледувани се реакциите на некои оксокиселини $\left(\mathrm{HNO}_{3}, \mathrm{H}_{3} \mathrm{PO}_{4}, \mathrm{H}_{2} \mathrm{SO}_{4}, \mathrm{HClO}_{4}\right)$ со алкални метали $(\mathrm{Li}, \mathrm{Na}, \mathrm{K})$. Дадени се и видео записи на овие експерименти, како помош за експериментаторите кои немаат доволно искуство или хемикалии. Овој труд е продолжение на претходно објавениот труд кој е во врска со реакции на алкални метали со халогеноводородни киселини и е дел од серијата публикации под општ назив „Безбеден начин за изведување опасни експерименти“.
\end{abstract}

Клучни зборови: опасни експерименти; безбедносна кутија; алкални метали; оксокиселини 


\section{INTRODUCTION}

The reactions explained in this paper are not novel, but they have not been systematically studied, and the results have not been compared. Not all factors important for the reactions have been taken into consideration when explaining the rate and the reason for the velocity of the explosion occurring in some cases. This paper characterizes the reactions beyond the phenomenological approach and tries to sum up all the factors influencing the reactions and explaining all aspects of the process. In order to fill in this gap, as well as to point to a safe way of performing the corresponding demonstrations, we undertook this study as a continuation of the previous work. In this contribution we present the results of the reactions of $\mathrm{Li}, \mathrm{Na}$ and $\mathrm{K}$ with concentrated aqueous solutions of oxoacids, namely with $\mathrm{HNO}_{3}(\mathrm{aq}), \mathrm{H}_{3} \mathrm{PO}_{4}(\mathrm{aq}), \mathrm{H}_{2} \mathrm{SO}_{4}(\mathrm{aq})$ and $\mathrm{HClO}_{4}(\mathrm{aq})$.

The present paper is, in a way, the expected extension to the previously published work that dealt with the reactions of hydrohalic acids with alkali metals [1]. Both papers are continuations of a series concerning safety in performing dangerous experiments that was published in 2002 [2, 3]. The previous paper [1] reviews the available literature data and video materials of water-alkali metal reactions followed by systematic studies of the alkali metal-hydrohalic acid reactions.

Alkali metals are of key importance in all curricula around the world. The present set of experiments may serve as an upgrade to the curricula, at least for the talented and/or curious students. The authors believe they can increase the students' passion for chemistry. Given that the safety box is used as advised, the experiments can be performed virtually everywhere. It is expected that the demonstrations/experiments will be welcomed by both high school and university students. Needless to say, the instructor must be well prepared for the demonstrations to be performed. As always, one should bear in mind never to perform a chemistry experiment that has not been performed earlier (at least a couple of times) by oneself.

\section{BRIEF REVIEW OF RELATED WORKS}

Even though this subject matter seems simple and known, there are not many published results dealing with the reactions of the alkali metals and acids [4-8]. Most of them just mention these reactions from a phenomenological point of view, and the reactions refer mainly to dilute oxoacids.

Besides the well known reactions of alkali metals with water [9-16], it is quite difficult to find relevant explanations about the reactions of alkali metals with concentrated oxoacids. Most of the text books in general and inorganic chemistry deal with the reactions of the alkali metals with diluted oxoacids, only taking into consideration the increase in the reactivity of the alkali metals. Also, many videos posted on different on-line platforms are unsatisfactory, performed very unprofessionally with high risk of injury for both the experimenter and spectators; also, many of them offer incorrect descriptions of the chemism. That is the reason why those will not be referenced in the present paper.

The risk of unpredictable and violent explosion, as well as the potential hazard presented by the reactants themselves, makes these experiments unwanted as possible lecture demonstrations. One could imagine that the chemical reactions of alkali metals with concentrated acids, in most cases, present an even higher risk than the corresponding reactions with water (the reactions with acids are expected to be far more vigorous).

\section{THE SAFETY BOX (IMPROVED)}

In order not to avoid performing these types of dangerous experiments and still maintain and even increase the safety level, the construction of a so-called safety box was initiated, and it was employed when conducting these experiments. This feature was introduced in the previous paper [1] and now is slightly improved from a practical point of view. The main reason for that was the unknown outcome of the reaction, i.e. the extent of reactivity of the metals with strong oxoacids and the power of the possible explosion.

This safety box can be used in all cases where a hazard of explosion exists upon addition of a solid or liquid to a reaction system. Detailed explanations of the construction and functionality of the safety box are given in the previous paper [1]. Also, Figure 1 may help in understanding its design. The only (perhaps minor) new feature about this setup is the addition of a tray under the box that helps in the cleanup after spillage or explosion. 


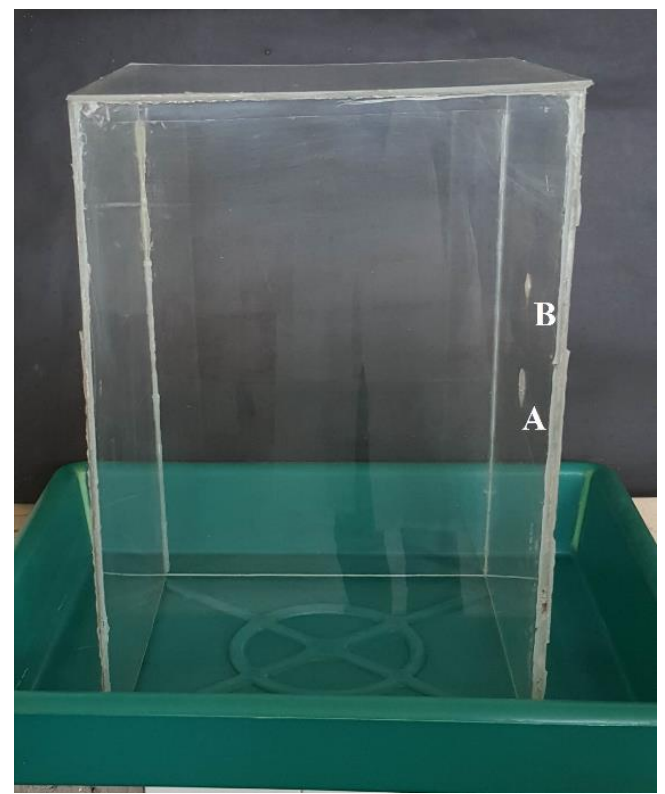

a)

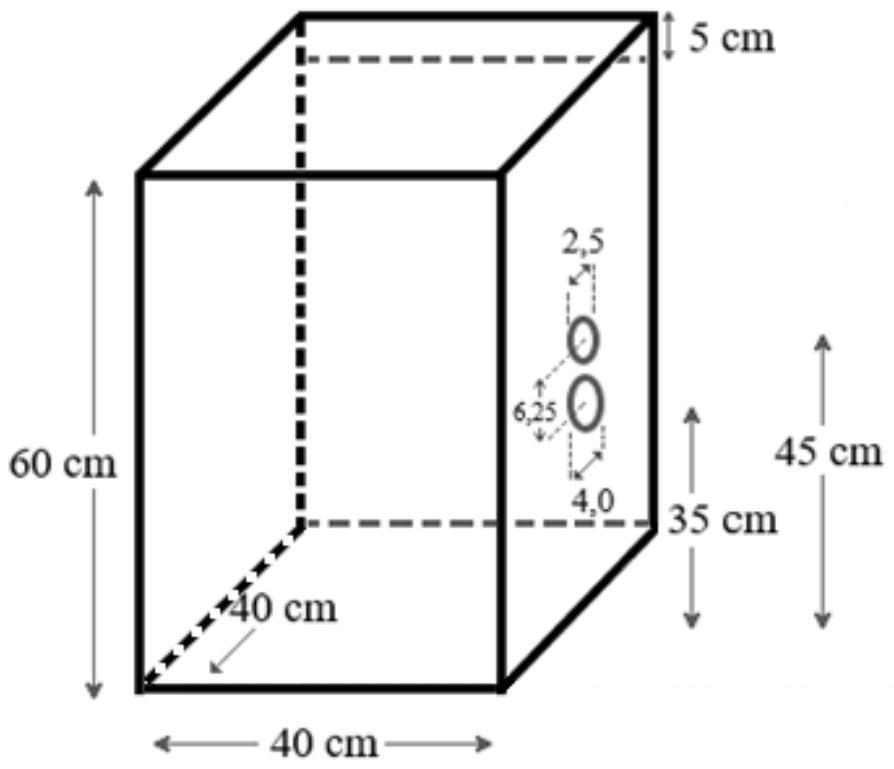

b)

Fig. 1. a) Safety box made of clear acrylic plates glued together with acrylic glue. Two circular openings (A and B) were made in the right-hand side plate. The tray under the box helps with the cleanup after the reaction; b) Schematic drawing of the constructed safety box.

\section{DEMONSTRATIONS}

All the experiments described here were performed using the safety box, due to the unknown outcomes. When using sodium or potassium we took $\sim 100 \mathrm{mg}$ of the metal, while in the reactions with lithium $\sim 30 \mathrm{mg}$ was used (less, because lithium is lighter and is the metal with the lowest molar mass, so the quantity is comparable to that of the sodium used). The volume of the pieces used was approximately the size of a green pea, except for lithium, where due to commercial availability (rice-grain size) $4-5$ pieces were used.

A test tube with $5 \mathrm{ml}$ of acid is clamped and placed in a glass jar (the latter is optionally filled with water to damp the effect of a possible explosion). All the above is then placed in the safety box (Fig. 2). Often it works well, but if the explosion is very violent (as is the case with nitric or perchloric acid), not only is the test tube shattered but the glass jar cracks as well. One of the options is to omit the water added to the jar, since it also acts as a medium that transfers the shock wave. On the other hand, if there is no water, after an explosion or spillage the contents (concentrated acids) will be spread around, leaving mess that is more difficult (concerning safety) to clean up. The option of using plastic jars was considered. However, the problem with plastic is that it catches fire easily and in most of the investigated reactions the metal catches fire and small lighted pieces are spread around. Instead of a glass jar, a laboratory beaker can be used or even an Erlenmeyer flask. Glass jars have much thicker walls and have the advantage of being cheap compared to standard laboratory glassware.

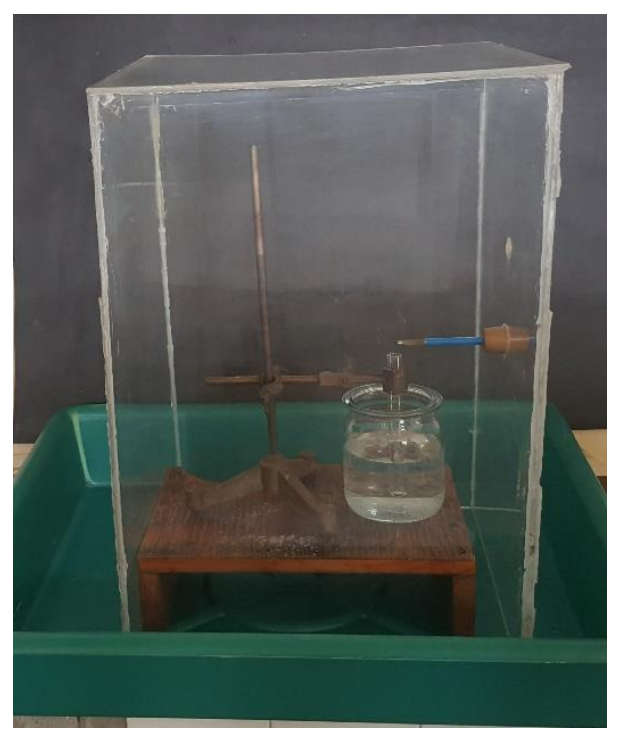

Fig. 2. Complete setup for all of the experiments described in this paper. The test tube is mounted on a metal stand by a boss head and metal clamp and immersed in a water-filled jar. The apparatus is positioned on a stand and placed inside the safety box.

The metal is added by a glass spoon (specifically designed for the safety box and built by 
a glassblower) from the opening "A" on the box (cf. Fig. 1). Alternatively, a mechanical pencil passing through a rubber stopper could be inserted in opening "B", or simply long tweezers $(>30 \mathrm{~cm})$, as in some of the cases described in this paper, can be used. The level of safety decreases in the order: remote glass safety spoon, mechanical pencil, tweezers. The best option for the safety of the experimenter is to use the remotely activated safety spoon, but the drawback is that in case of explosion the glass spoon will, almost inevitably, be broken.

\section{FACTS AND EXPECTATIONS}

The solubilities of the reaction products, as well as the strengths of the selected oxoacids in aqueous solution differ. Taking into consideration general chemistry knowledge one could draw a general conclusion that the stronger the acid and the higher the solubility of the obtained salt in water, the more vigorous the reaction is expected to be when alkali metals react with oxoacids. Thus, considering the solubility data of alkali salts (Table 1) and the $\mathrm{p} K_{\mathrm{a}}$ values for the four acids (cf. Table 2), one could expect $a$ priori that the reaction with $\mathrm{H}_{3} \mathrm{PO}_{4}$ should be the least spectacular, and those with $\mathrm{HClO}_{4}$ the most.

Table 1

\begin{tabular}{|c|c|c|c|}
\hline Anion $_{\text {Cation }}^{\text {Can }}$ & $\overline{\mathrm{Li}^{+}}$ & $\overline{\mathrm{Na}^{+}}$ & $\overline{\mathrm{K}^{+}}$ \\
\hline $\mathrm{NO}_{3}^{-}$ & 102.0 & 91.2 & 38.3 \\
\hline $\mathrm{PO}_{4}{ }^{3-}$ & 0.027 & 14.5 & 106.0 \\
\hline $\mathrm{HPO}_{4}{ }^{2-}$ & $10.0^{*}$ & 11.8 & 168.0 \\
\hline $\mathrm{H}_{2} \mathrm{PO}_{4}^{-}$ & $126.0^{*}$ & 94.9 & 25.0 \\
\hline $\mathrm{SO}_{4}^{2-}$ & 34.2 & 28.1 & 12.0 \\
\hline $\mathrm{HSO}_{4}^{-}$ & $25.7 * *$ & 28.5 & 50.6 \\
\hline $\mathrm{ClO}_{4}^{-}$ & 58.7 & 205.0 & 2.08 \\
\hline
\end{tabular}

*Wikipedia,

https://en.wikipedia.org/wiki/Solubility_table

(last accessed 15.8.2020)

**ChemBK, CAS database,

https://www.chembk.com/en/chem (last accessed 13.8.2020)

The electronegativity of the central atom (Table 2), besides the $\mathrm{p} K_{\mathrm{a}}$ value, is also a measure of acid strength. It is known that the strength of the oxoacid also increases with increasing electronegativity of the central atom. The central atom withdraws electrons from the $\mathrm{OH}$ group so the hydrogen atom is more likely to leave. On the other hand, there are many oxoacids containing additional oxygen atoms (not part of $\mathrm{OH}$ ). The additional electronegative oxygen atoms pull electron density from the $\mathrm{O}-\mathrm{H}$ bond, further increasing its polarity. The strength of the acid will increase by an increase in the electronegativity of the central atom and also by an increase in the number of oxygen atoms bonded to it.

The reactivity of oxoacids with alkali metals is further influenced by the possibility of obtaining hydrogen salts (acid salts). This complicates the reaction chemism and makes the reaction difficult to characterize by only one general equation. For example, in the case of the reaction of potassium and sulfuric acid, not only $\mathrm{K}_{2} \mathrm{SO}_{4}$ and $\mathrm{KHSO}_{4}$ can be obtained, but $\mathrm{K}_{3} \mathrm{HSO}_{4}$ can also be a possible product $[17,18]$.

\section{Table 2}

$p K_{a}$ values at $25^{\circ} \mathrm{C}$ of corresponding acids and electronegativity $(\chi)$ of the central atom [19]

\begin{tabular}{lcc}
\hline \hline $\mathrm{H}_{x} \mathrm{AO}_{y}$ & $\mathrm{p} K_{\mathrm{a}}$ & $\chi$ \\
\hline $\mathrm{HNO}_{3}$ & -1.3 & $(\mathrm{~N}) 3.04$ \\
& 2.16 & \\
$\mathrm{H}_{3} \mathrm{PO}_{4}$ & 7.21 & $(\mathrm{P}) 2.19$ \\
& 12.32 & \\
$\mathrm{H}_{2} \mathrm{SO}_{4}$ & -3.0 & $(\mathrm{~S}) 2.58$ \\
$\mathrm{HClO}_{4}$ & 1.92 & (Cl) 3.16 \\
\hline \hline
\end{tabular}

\section{EXPERIMENTAL}

\subsection{General settings}

Strict precautions were taken for the safety of the experimenter when handling the acids as well as the alkali metals. The tweezers and knife used in the experiments were dried thoroughly. All experiments conducted for the first time were performed in a fume hood using the safety box to provide additional safety against possible explosion.

\subsection{Chemicals}

All chemicals were of reagent grade. The acids used in the experiments were simply called "concentrated acids" with mass fractions of at least $70 \%$. All were commercially available. The data on the acids provided by the manufacturers are shown in Table 3.

Lithium metal was taken from a freshly opened airtight container filled with argon and used with no additional purification. Sodium and potassium were kept under petroleum. For each reaction a freshly cut piece was used. The 
corrosion coating was removed by cutting and the petroleum removed by filter paper. The freshly cut piece was then washed with hexane to remove the residual petroleum. Data on the alkali metals provided by the manufacturers are given in Table 4 .

T a b le 3

Important data on aqueous solutions of the oxoacids

\begin{tabular}{lcccc}
\hline \hline $\mathrm{H}_{x} \mathrm{AO}_{y}$ & $w / \%$ & $\rho /\left(\mathrm{g} \mathrm{cm}^{-3}\right)$ & $M_{\mathrm{r}}$ & Grade \\
\hline $\mathrm{HNO}_{3}$ & 70 & $1.413\left(20^{\circ} \mathrm{C}\right)$ & 63.01 & for analysis \\
$\mathrm{H}_{3} \mathrm{PO}_{4}$ & 85 & $1.685\left(25^{\circ} \mathrm{C}\right)$ & 98.00 & for analysis \\
$\mathrm{H}_{2} \mathrm{SO}_{4}$ & 98 & $1.840\left(25^{\circ} \mathrm{C}\right)$ & 98.08 & for analysis \\
$\mathrm{HClO}_{4}$ & 70 & $1.664\left(25^{\circ} \mathrm{C}\right)$ & 100.46 & for analysis \\
\hline \hline
\end{tabular}

Table 4

Data on the alkali metals given by the manufacturer

\begin{tabular}{lrcc}
\hline \hline Metal & $w / \%$ & $\rho / \mathrm{g} \mathrm{cm}^{-3}$ & $M_{\mathrm{r}}$ \\
\hline $\mathrm{Li}$ & $\geq 99$ & $0.53\left(20^{\circ} \mathrm{C}\right)$ & 6.941 \\
$\mathrm{Na}$ & $\geq 99$ & $0.97\left(20^{\circ} \mathrm{C}\right)$ & 22.99 \\
$\mathrm{~K}$ & 98 & $0.86\left(25^{\circ} \mathrm{C}\right)$ & 39.10 \\
\hline \hline
\end{tabular}

\section{RESULTS AND DISCUSSION}

The chemical reactions of alkali metals with oxoacids cannot be described simply. The products obtained cannot be predicted by analogy without taking into consideration the experimental results. Each reaction of a metal with an acid has its own specific features, characteristic of each metal reacting with a given acid, so in most cases it is difficult to make a correct assumption. The strong oxidizing properties of the acids used contribute to the formation of side products that are a result of the additional oxidation of the main product of the chemical reaction.

A systematic investigation of the alkali metals and some oxoacids of the elements from Groups 15, 16 and 17 in the Periodic Table was conducted. The consideration and description of the reactions will be given in the following order:

- oxoacids of the elements in Group 15:

$\mathrm{HNO}_{3}, \mathrm{H}_{3} \mathrm{PO}_{4}$,

- oxoacids of the elements in Group 16: $\mathrm{H}_{2} \mathrm{SO}_{4}$,

- oxoacids of the elements in Group 17: $\mathrm{HClO}_{4}$.

All the reactions discussed in this paper are relatively trivial from the aspect of the main reaction that takes place. This reaction can be explained using the general chemical equations:

$$
\begin{gathered}
x \mathrm{M}(\mathrm{s})+\mathrm{H}_{x} \mathrm{AO}_{y}(\mathrm{aq}) \rightarrow \mathrm{M}_{x} \mathrm{AO}_{y}(\mathrm{~s}, \mathrm{aq})+(x / 2) \mathrm{H}_{2}(\mathrm{~g}) \\
(x-1) \mathrm{M}(\mathrm{s})+\mathrm{H}_{x} \mathrm{AO}_{y}(\mathrm{aq}) \rightarrow \mathrm{M}_{x-1} \mathrm{HAO}_{y}(\mathrm{~s}, \mathrm{aq})+(x-1) / 2 \mathrm{H}_{2}(\mathrm{~g}) \\
(x-2) \mathrm{M}(\mathrm{s})+\mathrm{H}_{x} \mathrm{AO}_{y}(\mathrm{aq}) \rightarrow \mathrm{M}_{x-2} \mathrm{H}_{2} \mathrm{AO}_{y}(\mathrm{~s}, \mathrm{aq})+(x-2) / 2 \mathrm{H}_{2}(\mathrm{~g})
\end{gathered}
$$

where $\mathrm{M}$ is the alkali metal $(\mathrm{Li}, \mathrm{Na}, \mathrm{K})$ and $\mathrm{H}_{x} \mathrm{AO}_{y}$ is the oxoacid $\left(\mathrm{HNO}_{3}, \mathrm{H}_{3} \mathrm{PO}_{4}, \mathrm{H}_{2} \mathrm{SO}_{4}\right.$ or $\left.\mathrm{HClO}_{4}\right)$.

\subsection{Reactions with $\mathrm{HNO}_{3}$}

\subsubsection{Lithium}

The products of the reaction of lithium and nitric acid can differ depending on the acid concentration. When a dilute acid is used, the main products are lithium nitrate and ammonium nitrate [20]:

$$
\begin{gathered}
8 \mathrm{Li}(\mathrm{s})+12 \mathrm{HNO}_{3}(\mathrm{aq}) \rightarrow 8 \mathrm{LiNO}_{3}(\mathrm{aq})+ \\
\mathrm{NH}_{4} \mathrm{NO}_{3}(\mathrm{aq})+3 \mathrm{H}_{2} \mathrm{O}(\mathrm{l})
\end{gathered}
$$

or in ionic form:

$$
\begin{gathered}
8 \mathrm{Li}(\mathrm{s})+2 \mathrm{NO}_{3}^{-}(\mathrm{aq})+10 \mathrm{H}^{+}(\mathrm{aq}) \rightarrow 8 \mathrm{Li}^{+}(\mathrm{aq})+ \\
\mathrm{NO}_{3}^{-}(\mathrm{aq})+\mathrm{NH}_{4}^{+}(\mathrm{aq})+3 \mathrm{H}_{2} \mathrm{O}(\mathrm{l})
\end{gathered}
$$

which is the more proper way of describing the process that takes place taking into consideration the number of exchanged electrons in a single act of chemical transformation.

There are some literature data (web pages) that offer very unlikely descriptions of the reaction products [21] that have been proven to be incorrect. According to this source, the reaction is suggested to follow the equation:

$$
3 \mathrm{Li}+4 \mathrm{HNO}_{3} \rightarrow 3 \mathrm{LiNO}_{3}+\mathrm{NO}+2 \mathrm{H}_{2} \mathrm{O}
$$

In the experiment conducted, no generation of NO was detected; on the other hand, the presence of $\mathrm{NH}_{4}{ }^{+}$in the previously proposed reaction was easily proven by the Nessler test, something that is not considered in the latter equation.

However, in this paper the main objective is to study the reactions of alkali metals with concentrated acids, so the reaction of lithium with concentrated $\mathrm{HNO}_{3}$ will be considered. According to the experiment, at the exact moment when the lithium comes into contact with nitric acid, an evolution of brown gas can be observed (Fig. 3, which shows five frames with a time interval of $0.1 \mathrm{~s}$ between them). From this figure, one can judge the speed of the reaction. The only ambiguity that exists is whether the formation of nitrogen monoxide precedes the formation of nitrogen dioxide, i.e., whether the $\mathrm{NO}_{2}$ is a result of NO oxidation. Nevertheless, the equation of the chemical reaction can be written as: 


$$
\begin{gathered}
\mathrm{Li}(\mathrm{s})+2 \mathrm{HNO}_{3}(\mathrm{aq}) \rightarrow \mathrm{LiNO}_{3}\left(\mathrm{aq}, \mathrm{HNO}_{3}\right)+\mathrm{NO}_{2}(\mathrm{~g}) \\
+\mathrm{H}_{2} \mathrm{O}\left(1, \mathrm{HNO}_{3}\right)
\end{gathered}
$$

In this equation it is explicitly stated that the products are actually dissolved in nitric acid since the medium in which the reaction takes place is mainly the acid itself.

This reaction is exothermic and vigorous and in many cases even explosive (when fresh lithium free of a corrosion layer is used, as in our case). Figure 4 shows the continuation of the reaction depicted in Figure 3. Approximately $1.0 \mathrm{~s}$ after the contact of lithium with the acid a small explosion occurs (Fig. 4c). The metal catches fire and after $0.25 \mathrm{~s}$ another more violent explosion takes place (Fig. 4e). From careful examination of the experiment and analysis of the frames it can be concluded that after the first explosion and after the metal ignites, the test tube cracks due to the high temperature, the water rushes in, and the second explosion takes place.

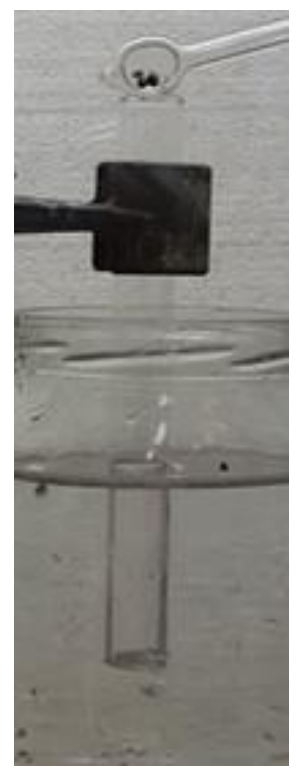

a)

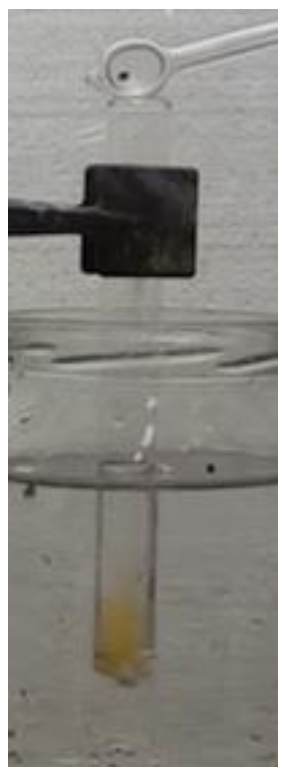

b)

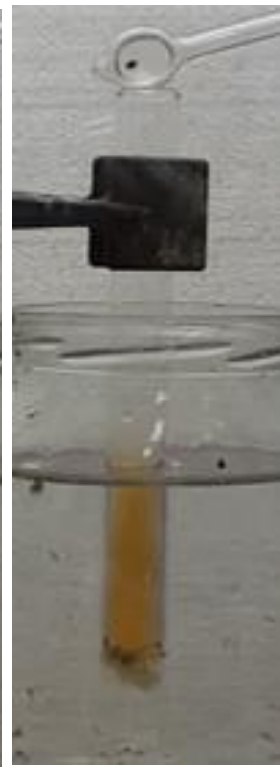

c)

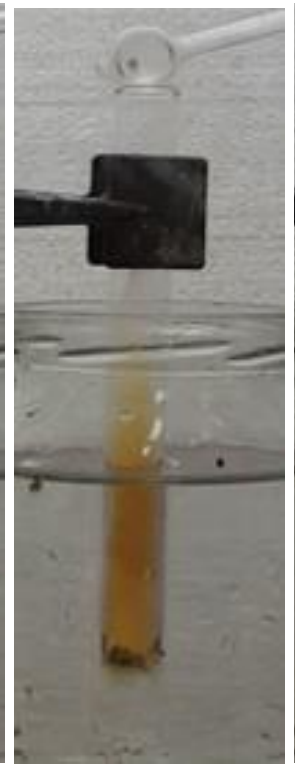

d)

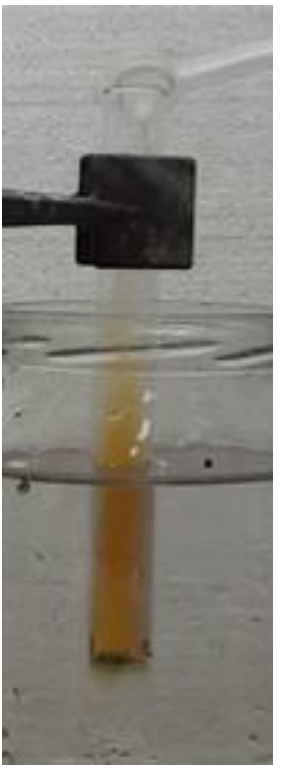

e)

Fig. 3. Reaction of lithium with concentrated $\mathrm{HNO}_{3}$ :

a) at the moment of addition; b) after $0.1 \mathrm{~s} ; \mathbf{c}$ ) after $0.2 \mathrm{~s}$; d) after $0.3 \mathrm{~s}$; and e) after $0.4 \mathrm{~s}$

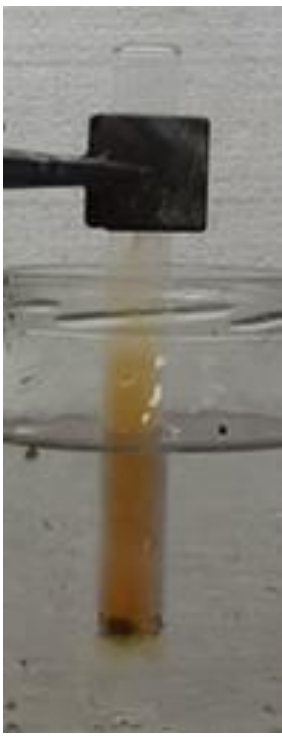

a)

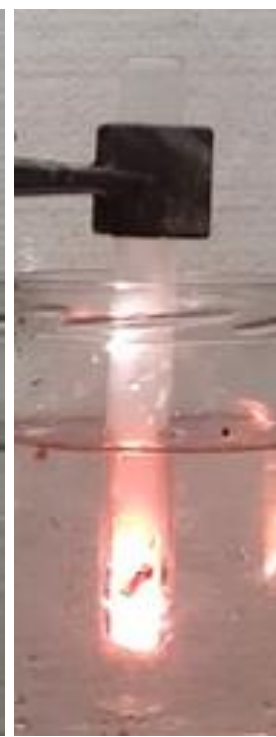

b)

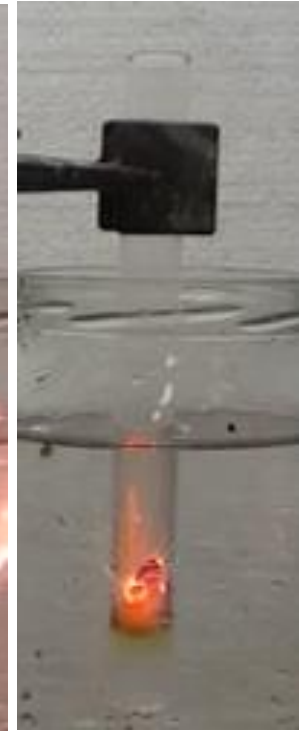

c)

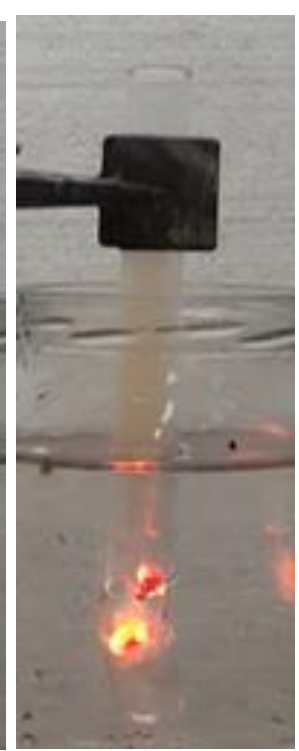

d)

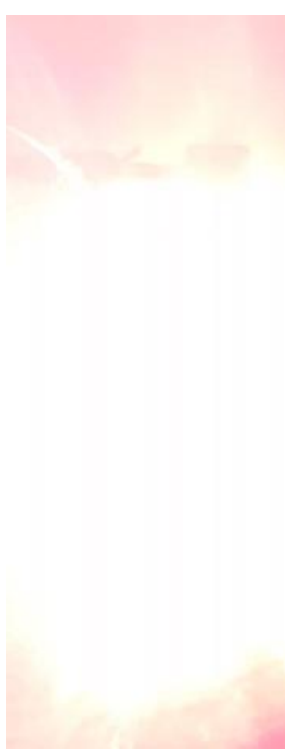

e)

Fig. 4. Reaction of lithium with concentrated $\mathrm{HNO}_{3}$. Each frame a) to e) are at 0.1 -s intervals, starting at $1.0 \mathrm{~s}$ from the beginning of the reaction 
When the entire process is considered, the conclusion can be drawn that the reaction is extremely vigorous and explosive, but the influence of the water cannot be neglected. This is especially noticeable and pronounced where the reaction of $\mathrm{Li}$ with $\mathrm{HClO}_{4}$ is observed at the moment when water is added. Based on these conclusions, the reaction was conducted in a laboratory beaker (Fig. 5). In this case, no local overheating develops, so the reaction was less vigorous as observed in the first part of the reaction in the test tube (Fig. 4).
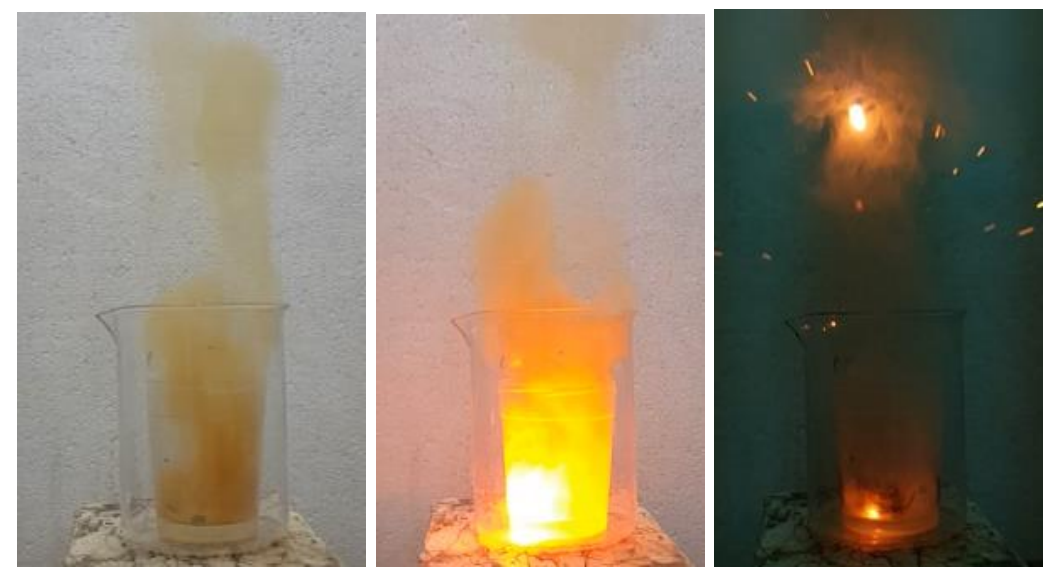

Fig. 5. Reaction of lithium with concentrated $\mathrm{HNO}_{3}$ performed in laboratory beaker

The lithium nitrate obtained is very soluble in water (Table 1), so the common-ion effect will not decrease the solubility to a level that could affect the rate of reaction. At the end a cloudy white solution can be seen (when the reaction is conducted in the beaker). The increased temperature and the pronounced oxidation properties of $\mathrm{HNO}_{3}$ enable the reaction to proceed. The reason for the second explosion in the test tube is that the water removes part of the product and the reaction becomes more intense. An alternative explanation for the strong explosion of the ball of molten lithium (upon its contact with water) can be offered in terms of a Coulomb explosion [22]. A careful inspection of the video file in slow motion reveals that: (1) the hydrogen displaced in one of the parallel reactions ignites with a pop (witnessed by its burning flame); (2) the pieces of lithium melt and unite into a larger molten ball; (3) as the flame subsides and disappears, the red-hot lithium ball explodes. The explosion is very violent, accompanied by a strong flash and seemingly "comes out of nothing", as the flame has already diminished. It seems very likely that the latter explosion (which is so violent that it cracks both the test tube and the jar) is a real Coulomb explosion. This process, we believe, is initiated by electrostatic repulsion within the layer of lithium ions formed at the surface of the molten metal and caused by an immediate release of the valence electrons into the acid solution. The resulting instability leads to the formation of metal spikes that shoot into the water
[22]. This process, in turn, produces a new surface at which the heterogeneous alkali metal-acid solution reaction can propagate further in an explosive way. We shall elaborate more on this in a subsequent study [23].

\subsubsection{Sodium}

The conclusion that the reaction of sodium with concentrated nitric acid is more vigorous compared to that of lithium can be drawn based on the slow motion of the recorded video. It is noticeable that at the exact moment when the sodium comes into contact with the acid, the liberated hydrogen is instantaneously ignited and a vigorous reaction takes place (Fig. 6). Unlike the case of lithium, the reaction of sodium and $\mathrm{HNO}_{3}$ proceeds faster and the explosion occurs $0.8 \mathrm{~s}$ after the contact of the metal with the acid. At a certain moment the hydrogen stops burning and immediately afterwards a small explosion takes place igniting both the hydrogen and the (already) molten sodium. After $1.2 \mathrm{~s}$ from this moment (Fig. 6e), another explosion takes place. This explosion is more pronounced but might be a result of the overheating of the reaction mixture and the cracking of the test tube. The latter explosion is somewhat similar to the second explosion seen in the case of lithium, but it does not seem to be a Coulomb explosion. Why the difference in the behavior? It may simply result from the different quantities of lithium and sodium used in the 
experiments (the smaller the quantity, the less likely it is that the conditions for a Coulomb explosion will be met). Alternatively, the rate of reaction with $\mathrm{HNO}_{3}$ is expected to be greater with sodium than with lithium, so it may just be that the sodium reacts much faster than lithium.

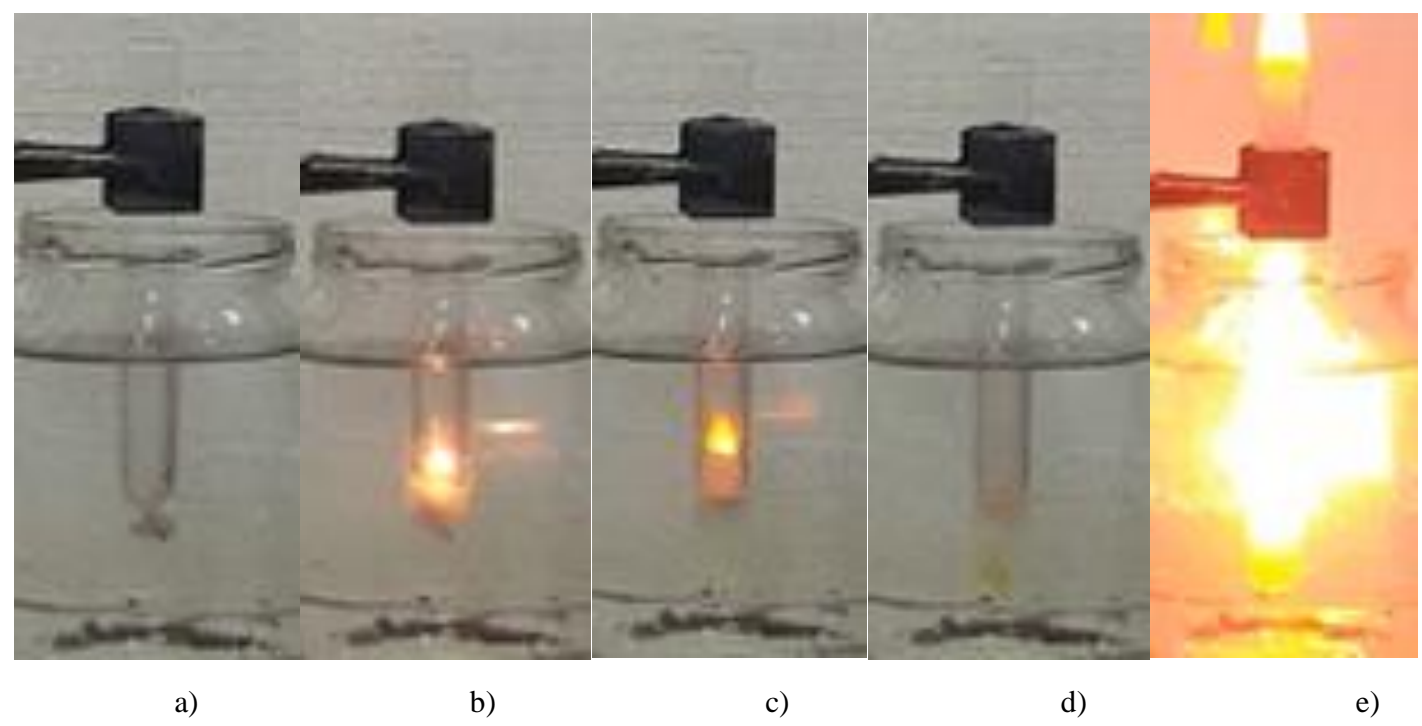

Fig. 6. Reaction of sodium with concentrated $\mathrm{HNO}_{3}$ : a) the moment of addition of the metal to the acid; b) the hydrogen is instantaneously ignited; c) the hydrogen burns but not the metal; d) the ignited hydrogen stops burning; and e) an explosion occurs.

A proof that the generated gas is hydrogen can be based exclusively on the moment when the gas is ignited. Unlike the reaction with lithium, in this case no oxides of nitrogen are generated. Here again, lithium differs from the rest of the alkali metals (diagonal relations in the Periodic Table; lithium is in many instances closer to magnesium $[24,25])$. The chemical reaction that takes place could be explained in terms of the simple equation:

$$
2 \mathrm{Na}(\mathrm{s})+2 \mathrm{HNO}_{3}(\mathrm{aq}) \rightarrow 2 \mathrm{NaNO}_{3}\left(\mathrm{aq}, \mathrm{HNO}_{3}\right)+\mathrm{H}_{2}(\mathrm{~g})
$$

The main product of this reaction - sodium nitrate, just as lithium nitrate, is readily soluble in water, so it is not expected that the product will have any impact on the rate of the reaction. However, the common-ion effect lowers the solubility and this is perhaps visible when water gets into the reaction mixture and the second explosion occurs. Here too, one cannot exclude the possibility of a Coulomb explosion [22].

\subsubsection{Potassium}

The expectation that the reaction of potassium with concentrated nitric acid would be the most vigorous one in the series $\mathrm{Li}, \mathrm{Na}, \mathrm{K}$ are in line with the experimental data. The rate of this reaction is higher than those of the other two metals. It can be observed that the reaction starts instantaneously when the metal touches the acid and, at the same time, it is vigorous right from the very beginning (Fig. 7a). The liberated hydrogen ignites at the very first moment, and it burns until a violent explosion occurs (Fig. 7c).

On a timed basis, the reaction of potassium with nitric acid is undoubtedly the fastest compared to the other two. Figure 7 depicts the rate and the vigorous nature of the reaction. From the moment of contact between the metal and the acid until the explosion, only $0.6 \mathrm{~s}$ passes, which indicates the fastest and, at the same time, the most vigorous reaction.

Taking the products into consideration, the reaction resembles that of sodium with nitric acid. It is more than clear that the generated gas is hydrogen since it starts burning at the same time as the reactants come into contact. It is obvious that no oxides of nitrogen $\left(\mathrm{NO}\right.$ or $\left.\mathrm{NO}_{2}\right)$ are generated, since the gas above the reaction mixture is colorless.

Just as with lithium and sodium nitrates, the main product, potassium nitrate, is very soluble in water (Table 1). Due to the short reaction time until the explosion occurs, there is no opportunity for larger amounts of the product to be formed. This means that there will be no drastic increase in the concentration of $\mathrm{KNO}_{3}$ leading to a decrease in solubility. Even so, the common-ion effect is expected to be virtually insignificant. The pronounced reducing properties of potassium on one hand and the strong oxidizing characteristics of 
nitric acid on the other lead to a vigorous reaction followed by an explosion.

Knowing the products of the chemical reaction, the equation describing the process can be written as:

$$
2 \mathrm{~K}(\mathrm{~s})+2 \mathrm{HNO}_{3}(\mathrm{aq}) \rightarrow 2 \mathrm{KNO}_{3}\left(\mathrm{aq}, \mathrm{HNO}_{3}\right)+\mathrm{H}_{2}(\mathrm{~g})
$$

Once again, no traces of $\mathrm{NO}_{2}$ seem to be present among the products.

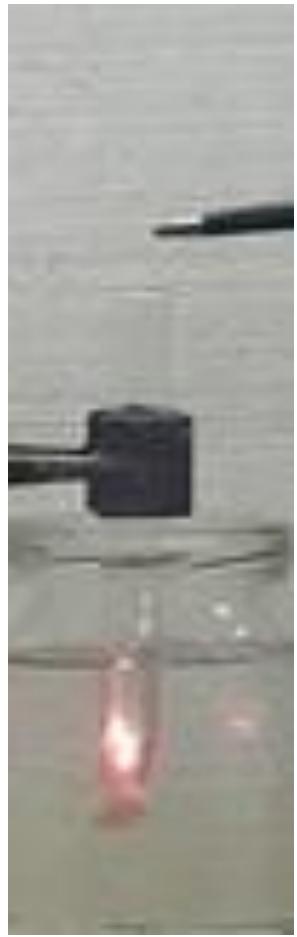

a)

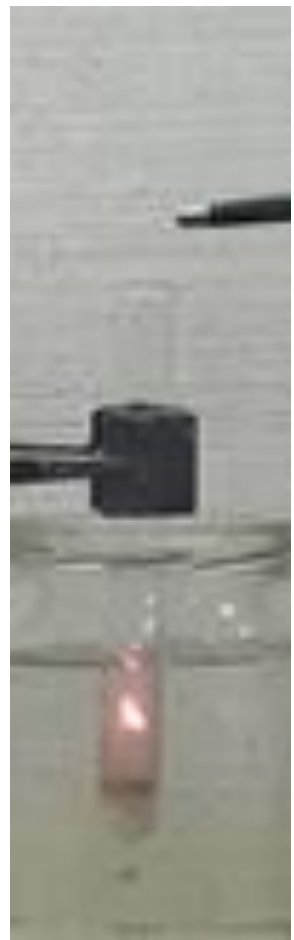

b)

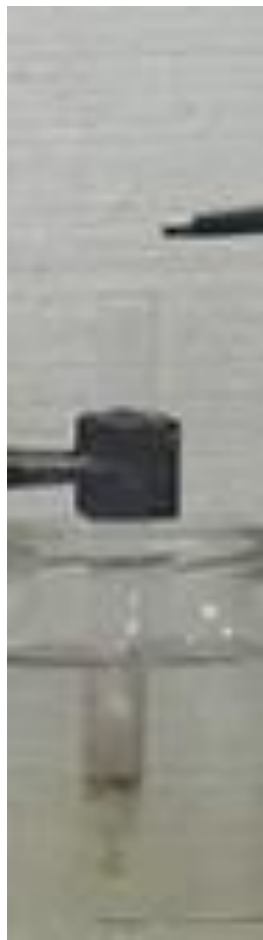

c)

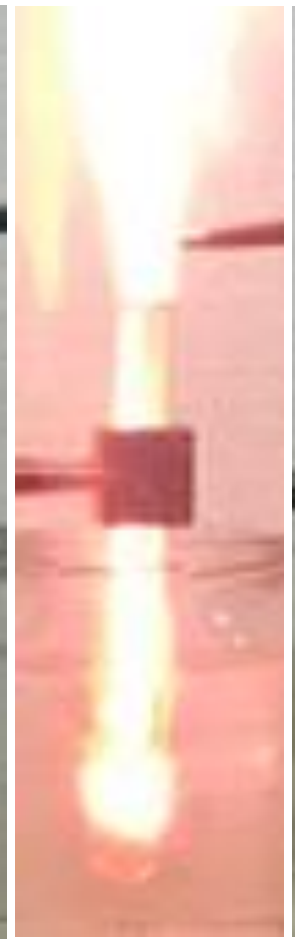

d)

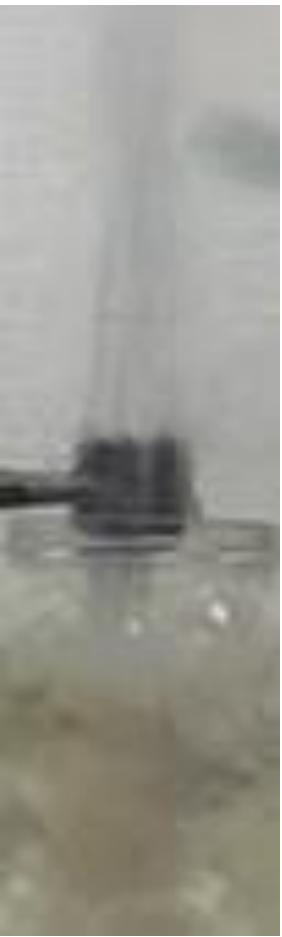

e)

Fig. 7. Reaction of potassium with concentrated nitric acid: a) at the moment of contact, the liberated hydrogen ignites; b) and c) the hydrogen burns but not the metal; d) and e) an explosion takes place

\subsection{Reactions with $\mathrm{H}_{3} \mathrm{PO}_{4}$}

The reactions of the alkaline metals with concentrated phosphoric acid are by far the least spectacular. That is due to the fact that concentrated phosphoric acid is significantly weaker than the other acids that we worked with and one of the weakest inorganic acids overall. The experimental results of the reactivity are in line with expectations on the basis of the value of the first dissociation constant (Table 2).

In addition, the viscosity of the acid plays an important role in the reaction rate. The more viscous the fluid, the slower the reaction, and data on the dynamic viscosity of the oxoacids used in this work are given in Table 3. According to these data, it can be concluded that phosphoric acid is the most viscous liquid of all the acids used (Table 5).

One of the reasons for the slow reactions of alkali metals with concentrated phosphoric acid is the high viscosity of the acid, despite its high concentration (i.e. its mass fraction).
T a ble 5

Dynamic viscosity of the oxoacids used

\begin{tabular}{lccc}
\hline \hline Acid & $\begin{array}{c}\text { Mass } \\
\text { fraction (\%) }\end{array}$ & $\begin{array}{c}\text { Dynamic } \\
\text { viscosity (Pa s) }\end{array}$ & Reference \\
\hline $\mathrm{HNO}_{3}$ & 70 & 0,76 & {$[26]$} \\
$\mathrm{H}_{2} \mathrm{SO}_{4}$ & 98 & 20,1 & {$[27]$} \\
$\mathrm{H}_{3} \mathrm{PO}_{4}$ & 85 & 43,4 & {$[28]$} \\
$\mathrm{HClO}_{4}$ & 70 & 4,06 & {$[29]$} \\
\hline \hline
\end{tabular}

On the other hand, if the densities of the acids are compared (Table 3), sulfuric acid has the highest value of density, but the reaction with sulfuric acid is more vigorous (see the section on $\mathrm{H}_{2} \mathrm{SO}_{4}$ ) than to the reaction with $\mathrm{H}_{3} \mathrm{PO}_{4}$. The densities of these two acids with same mass fraction $(98 \%)$ are not very different: $1.844 \mathrm{~g} / \mathrm{ml}$ [30] and $1.831 \mathrm{~g} / \mathrm{ml}$ [19] for phosphoric and sulfuric acid, respectively. According to these density values and the experimental results, it can be concluded that density does not play a significant role. Despite the 
close density values, one of the reactions (with $\mathrm{H}_{2} \mathrm{SO}_{4}$ ) is faster and more vigorous. These results lead to the conclusion that, after all, viscosity is a factor that affects the rate of the reaction besides acid strength and cannot be neglected in these considerations. The effect of viscosity may be interpreted by the contact between the metal and the acid. In highly viscous liquids, the acid diffuses much more slowly than in less viscous (dilute) solutions and the acid molecules (or ions) collide less frequently [31]. Thus, the reaction rate decreases rapidly with increasing solvent viscosity. In other words, the acid needs additional time to come into close contact with the metal (induction period) so the reaction can proceed. This effect is noticeable in the case of the reaction of $\mathrm{Li}$ with $\mathrm{H}_{3} \mathrm{PO}_{4}$.

\subsubsection{Lithium}

When a piece of lithium is added to concentrated phosphoric acid, a slow reaction takes place and gaseous hydrogen is released (Fig. 8).

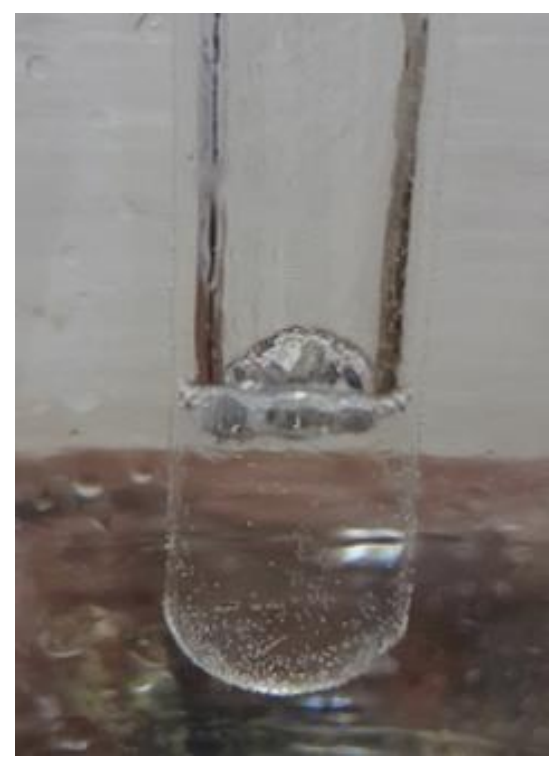

a)

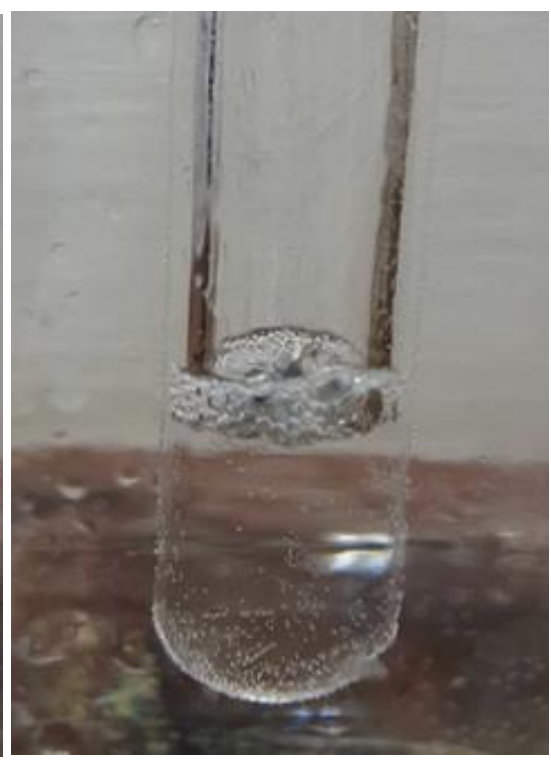

b)

Fig. 8. Reaction of lithium with concentrated phosphoric acid: a) $3.0 \mathrm{~s}$ after the addition of lithium; b) $2.5 \mathrm{~min}$ from the beginning of the reaction

The reaction is quite slow and is accompanied by hydrogen liberation. The energy released is not sufficient to ignite either the hydrogen or the lithium. In fact, the reaction is so slow that there is not enough hydrogen liberated during a reasonable time such that it can be lit by a match. The reaction ceases relatively peacefully by "dissolving" the entire piece of lithium in the acid. The reaction can be described by the equation:

$$
2 \mathrm{Li}(\mathrm{s})+2 \mathrm{H}_{3} \mathrm{PO}_{4}(\mathrm{aq}) \rightarrow 2 \mathrm{LiH}_{2} \mathrm{PO}_{4}(\mathrm{aq})+\mathrm{H}_{2}(\mathrm{~g})
$$

Since phosphoric acid is a weak acid it is common for hydrogen salts, such as hydrogen and dihydrogen phosphates, to be formed too. The solubility of lithium phosphates $\left(\mathrm{Li}_{3} \mathrm{PO}_{4}, \mathrm{Li}_{2} \mathrm{HPO}_{4}\right.$ and $\mathrm{LiH}_{2} \mathrm{PO}_{4}$ ), shown in Table 1 , are relatively low. This fact, together with the common-ion effect, can contribute to the lowering of the rate of the reaction. This reaction is by far the slowest of all the reactions studied in this work. The low rate can also be due to phosphoric acid being a very weak oxidizing agent.

\subsubsection{Sodium}

The reactivity (i.e., reaction rate) of sodium with concentrated phosphoric acid is greater compared to that with $\mathrm{Li}$, but still lower than the other studied reactions. The very beginning of the reaction is quite settled and slow. After few seconds the reaction speeds up as heat is generated (Fig. 9). An interesting observation is that during the reaction, even though sufficient heat seems to be released, the hydrogen does not ignite. On the other hand, the metal melts and catches fire (Fig. $9 \mathrm{c})$. At the very end of the reaction, an explosion occurs (Fig. 9d, 9e). 


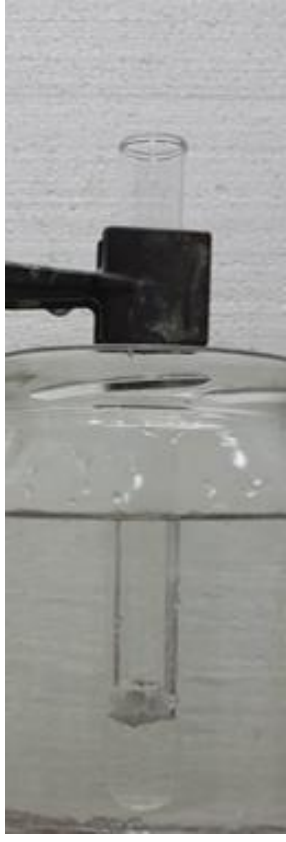

a)

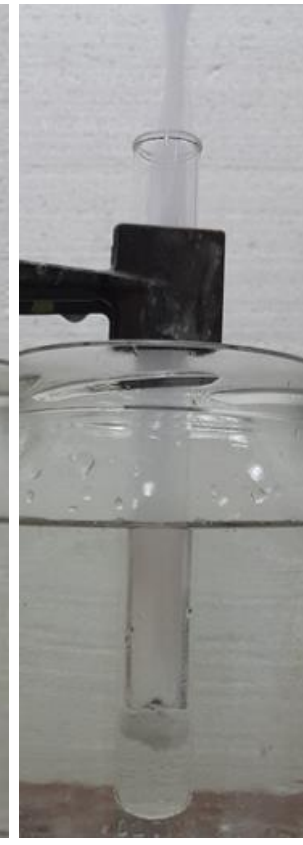

b)

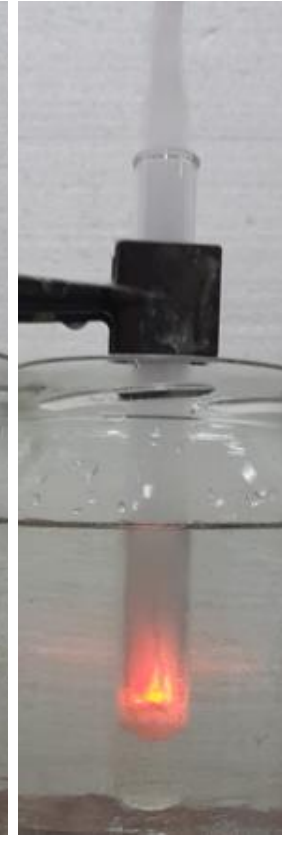

c)

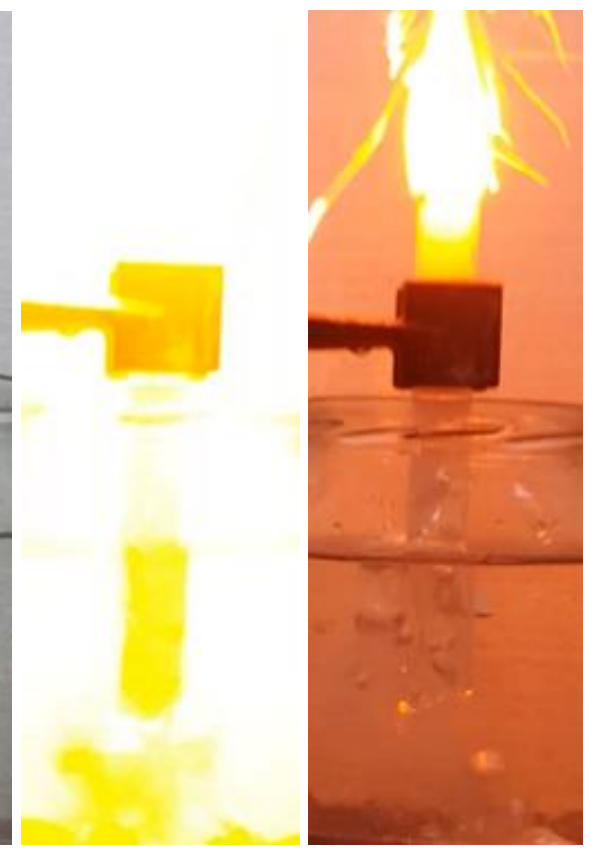

d)

e)

Fig. 9. Reaction of sodium with concentrated phosphoric acid: a) at the beginning of the reaction; b) the displaced hydrogen does not burn, and an aerosol is released; c) the metal melts and catches fire, but not the hydrogen; d) and e) explosion occurs

The reason why the hydrogen does not ignite probably lies in the fact that the phosphoric acid particles become dispersed and an aerosol is produced. In addition, the particles of solid product formed on the surface of the metal are also carried to the surface and enrich the aerosol with nonflammable constituents that restrict the hydrogen from burning. Only $0.55 \mathrm{~s}$ after the metal catches fire an explosion occurs and the burning metal is thrown out of the reaction system (Fig. 9e). The chemical equation characterizing the process is:

$$
2 \mathrm{Na}(\mathrm{s})+2 \mathrm{H}_{3} \mathrm{PO}_{4}(\mathrm{aq}) \rightarrow 2 \mathrm{NaH}_{2} \mathrm{PO}_{4}(\mathrm{aq})+\mathrm{H}_{2}(\mathrm{~g})
$$

As in the case of the reaction of $\mathrm{Li}$ with $\mathrm{H}_{3} \mathrm{PO}_{4}$, the written equation is not the only one that represents what happens in the system. The burning of the metal and the released heat contribute to generating other salts (side products). Also, the formation of diphosphates is not excluded. In Fig. 9b it can be seen that a white phosphate precipitate is produced during the reaction. According to Table 1 it is noticeable that the sodium salts obtained in this reaction are some of the less soluble in water. In this case one should take into consideration not only the formation of other salts of low solubility, but also the common-ion effect.

\subsubsection{Potassium}

As expected, the reaction of potassium with phosphoric acid is the most vigorous in this series of reactions with $\mathrm{H}_{3} \mathrm{PO}_{4}$. Potassium is the metal with the highest reactivity among the series $\mathrm{Li}, \mathrm{Na}$ and $\mathrm{K}$. However, if a comparison with the reactions of potassium with the other acids is made, this one is the slowest (again, that is what one would expect).

At the instant when potassium comes into contact with the acid, a relatively vigorous reaction starts, accompanied by release of heat and generation of hydrogen. The heat released is sufficient to ignite the hydrogen (Fig. 10c), something that is not observed in the reactions of $\mathrm{Li}$ and $\mathrm{Na}$. The metal does not ignite at the same time as the hydrogen, but before $(1.7 \mathrm{~s}$ from the beginning of the reaction). The metal continues to burn until the end of the reaction when a minor explosion is detected.

This reaction offers an important clue in confirming the gaseous products of the reactions of the entire series of alkali metals with $\mathrm{H}_{3} \mathrm{PO}_{4}$. The nature of the gas is confirmed to be hydrogen since the generated gas ignites. After a short time, the aerosol formed pushes the fire up the test tube (Fig. 10c), and at a certain point the fire is extinguished (Fig. 10d). Then, only a white smoke (aerosol) can be seen coming out of the test tube mouth (Fig. 10e). The metal continues to burn, but it cannot ignite the gas that is now part of the aerosol.

Analogously to the reactions of $\mathrm{Li}$ and $\mathrm{Na}$, the chemical equation describing the process can be written as: 


$$
2 \mathrm{~K}(\mathrm{~s})+2 \mathrm{H}_{3} \mathrm{PO}_{4}(\mathrm{aq}) \rightarrow 2 \mathrm{KH}_{2} \mathrm{PO}_{4}(\mathrm{aq})+\mathrm{H}_{2}(\mathrm{~g})
$$

Also in this case, a white precipitate is noticed to form under the reacting metal (Fig. 10c).
As in the other two cases (reactions with $\mathrm{Li}$ and $\mathrm{Na}$ ), hydrogen salts are likely to be formed, but the formation of other types of phosphates (diphosphates) cannot be precluded.

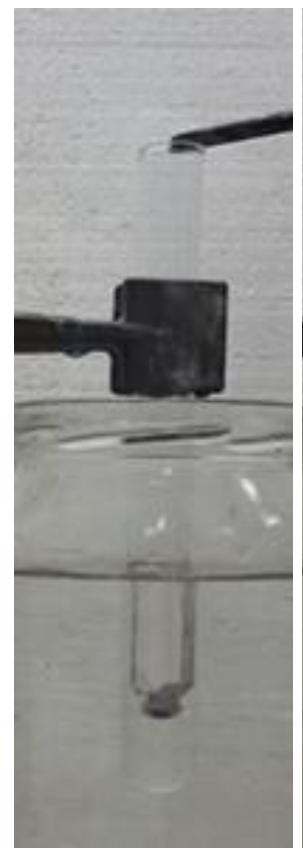

a)

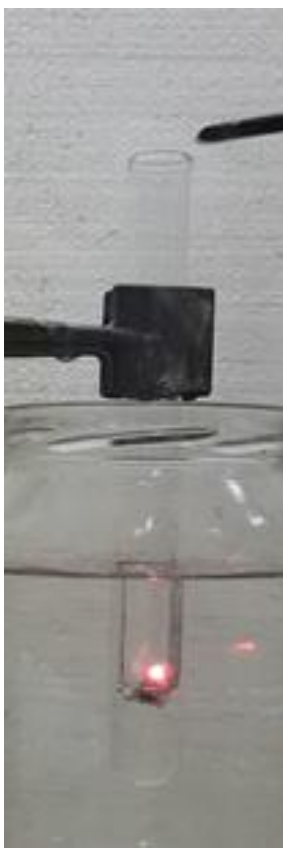

b)

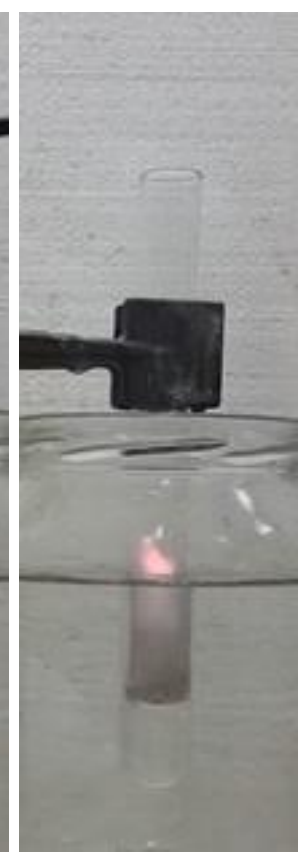

c)

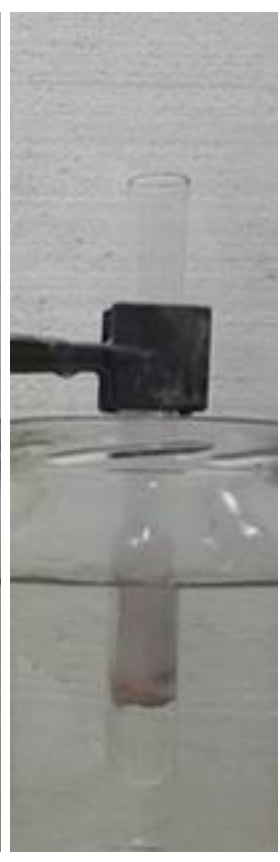

d)

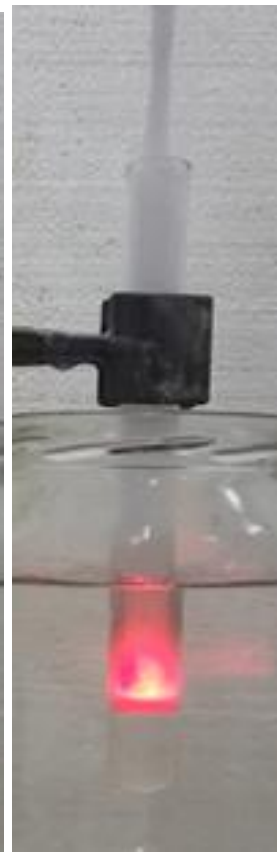

e)

Fig. 10. Reaction of potassium with concentrated phosphoric acid: a) the beginning of the reaction; b) the generated hydrogen ignites; c) the aerosol formed suffocates the burning hydrogen; d) the burning of the hydrogen stops; e) the metal is heated to red heat and catches fire

\subsection{Reactions with $\mathrm{H}_{2} \mathrm{SO}_{4}$}

There is a certain analogy between the reactions of the alkali metals with nitric and sulfuric acid. Similarities are expected in the reactions of the same alkali metal with almost equally strong oxidizing agents (acids). The leveling effect of strong acids in aqueous solution should also be taken into consideration. The only difference between nitric and sulfuric acids is their density and viscosity.

\subsubsection{Lithium}

There are differences when lithium reacts with dilute and concentrated sulfuric acid. When the dilution is high (no strict line can be set), the reaction can be described by the equation:

$$
2 \mathrm{Li}(\mathrm{s})+\mathrm{H}_{2} \mathrm{SO}_{4}(\mathrm{aq}) \rightarrow \mathrm{Li}_{2} \mathrm{SO}_{4}(\mathrm{aq})+\mathrm{H}_{2}(\mathrm{~g})
$$

When concentrated sulfuric acid is used, the products are different:

$$
\begin{gathered}
2 \mathrm{Li}(\mathrm{s})+3 \mathrm{H}_{2} \mathrm{SO}_{4}(\mathrm{l}) \rightarrow 2 \mathrm{LiHSO}_{4}\left(\mathrm{H}_{2} \mathrm{SO}_{4}\right)+\mathrm{SO}_{2}(\mathrm{~g}) \\
+2 \mathrm{H}_{2} \mathrm{O}\left(\mathrm{H}_{2} \mathrm{SO}_{4}\right)
\end{gathered}
$$

A proof that hydrogen gas is not released when concentrated acid is used is that the gas does not ignite when the lithium catches fire, unlike when dilute acid is used. The lithium catches fire after $2.5 \mathrm{~s}$ from the beginning of the reaction (Fig. 11b). Naturally, when lithium reacts with concentrated sulfuric acid, a hydrogen salt is obtained instead of the pure sulfate [32]. This can be further confirmed by the equation:

$$
\mathrm{Li}_{2} \mathrm{SO}_{4}(\mathrm{~s})+\mathrm{H}_{2} \mathrm{SO}_{4}(\mathrm{l}) \rightarrow 2 \mathrm{LiHSO}_{4}(\mathrm{~s})
$$

So, the entire sulfate obtained in the reaction is transformed to hydrogen sulfate, since there is a large excess of sulfuric acid and the reaction medium can be considered to be practically waterfree.

At the very beginning when the piece of lithium comes into contact with the acid, the reaction is relatively slow. The metal reacts slowly with the acid and formation of gas bubbles can be observed. The literature data suggest that the corrosion layer is being dissolved during this initial period, and immediately afterwards a vigorous reaction takes place. Based on the experiments 
conducted, this statement and explanation can be ruled out. The lithium used in these experiments was fresh, stored in an argon atmosphere and opened immediately before the experiments were conducted. There was no corrosion layer present, but some time was still required before the reaction proceeded faster. A more plausible explanation could be offered based on the increased oxidizing properties of the hot sulfuric acid and its viscosity. In the initial period, the reaction is slow (Fig. 11a) because of the high viscosity of sulfuric acid [32], but due to its exothermic character, the temperature rises in the course of the reaction and heats the medium. Both the increased temperature and oxidizing properties of hot $\mathrm{H}_{2} \mathrm{SO}_{4}$ contribute to the increased rate.

After $2.60 \mathrm{~s}$ from the beginning of the reaction, the heat released is sufficient to melt and ignite the metal (Fig. 11b), and a light explosion then takes place (Fig. 11c). In the performed experiment, it took $0.70 \mathrm{~s}$ for the explosion to occur after the lithium caught fire.

In Fig. 11c, the crimson red color of the flame suggests the presence of $\mathrm{Li}^{+}$ions in the system. After a while, when the temperature of the burning hydrogen rises, a yellow color of flame overtakes and covers the lithium red color. The yellow flame coloration is due to the sodium from the glass test tube. It should be noted that the hydrogen is generated when the test tube breaks and when the water enters the test tube. In that case, water comes into contact with the metal and dilutes the acid. In dilute acid, the gaseous product is hydrogen and when generated it starts to burn, since the lithium is already burning inside the test tube. If the same experiment is performed without the protection unit, no hydrogen is generated since there is no water to react with the lithium or to dilute the acid.

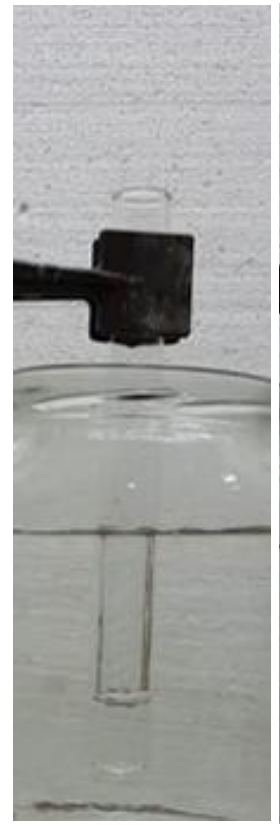

a)

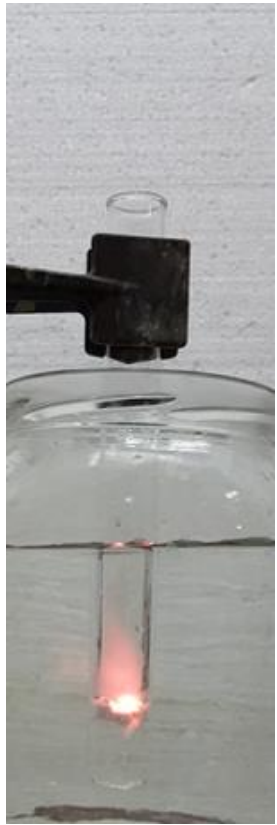

b)

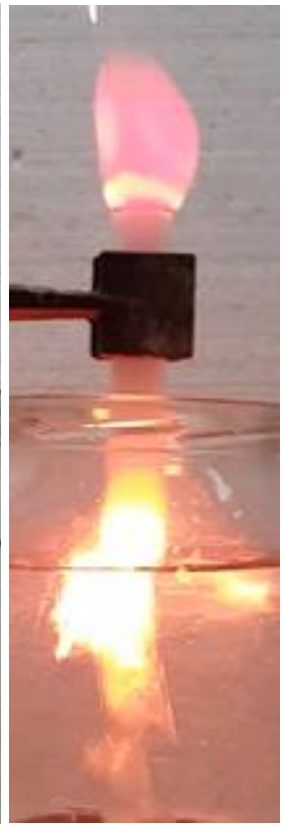

c)

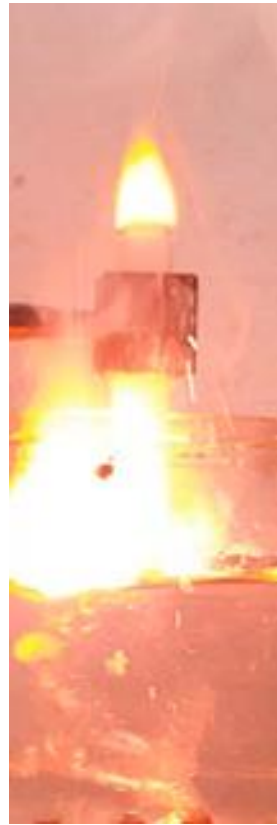

d)

Fig. 11. Reaction of lithium with concentrated sulfuric acid: a) at the moment of contact of the reactants; b) the lithium heats up and starts to burn; c) explosion; d) the metal and the hydrogen continue to burn

When the solubility of the products (both $\mathrm{Li}_{2} \mathrm{SO}_{4}$ and $\mathrm{LiHSO}_{4}$ ) are taken into consideration, it is clear that both are soluble in water and should not influence the rate of the reaction. However, this system can be considered as water-free, so it is not reasonable to consider the water solubilities of the products. There is only $2 \%(w / w)$ of water present. Taking into account that the reaction speeds up with time, it can be considered that the product does not stay on the metal surface and does not prevent it from further reaction with the acid. This means that the common-ion effect does not have a considerable influence on the reaction rate.

\subsubsection{Sodium}

The reaction of sodium metal with sulfuric acid is much more vigorous than lithium. This is in is line with expectations. It is also in line with the results of the previously performed experiments with nitric and phosphoric acids.

When the sodium metal is added to the test tube filled with concentrated sulfuric acid a 
reaction starts upon contact and is more vigorous than the analogous one with lithium. The rate of gas liberation is also faster. The hydrogen ignites spontaneously just after $0.35 \mathrm{~s}$ from the initial contact and the metal catches fire after $0.95 \mathrm{~s}$ from the moment of ignition (or $1.30 \mathrm{~s}$ after the beginning of the reaction). For comparison, it took $2.60 \mathrm{~s}$ for the lithium to ignite. As in the case of sodium and nitric acid, first the released hydrogen ignites, but not the metal (Fig. 12b and 12c) and in this case the explosion occurs some $0.60 \mathrm{~s}$ after the metal catches fire. This is another demonstration of the higher reactivity of sodium.

The reaction of sodium with concentrated sulfuric acid can be written using the equation:

$$
2 \mathrm{Na}(\mathrm{s})+\mathrm{H}_{2} \mathrm{SO}_{4}(\mathrm{l}) \rightarrow \mathrm{Na}_{2} \mathrm{SO}_{4}\left(\mathrm{H}_{2} \mathrm{SO}_{4}\right)+\mathrm{H}_{2}(\mathrm{~g})
$$

Since the reaction medium is pure sulfuric acid, the true reaction should be given by the equation:

$$
\mathrm{Na}_{2} \mathrm{SO}_{4}(\mathrm{~s})+\mathrm{H}_{2} \mathrm{SO}_{4}(\mathrm{l}) \rightarrow 2 \mathrm{NaHSO}_{4}\left(\mathrm{H}_{2} \mathrm{SO}_{4}\right)
$$

because the acid is in large excess, one can assume that only the reaction:

$$
2 \mathrm{Na}(\mathrm{s})+2 \mathrm{H}_{2} \mathrm{SO}_{4}(\mathrm{l}) \rightarrow 2 \mathrm{NaHSO}_{4}\left(\mathrm{H}_{2} \mathrm{SO}_{4}\right)+\mathrm{H}_{2}(\mathrm{~g})
$$

occurs. Both salts (sodium sulfate and sodium hydrogen sulfate) are very soluble in water, but, as in the previous reaction, the values of the solubilities are valid for aqueous solutions. The common-ion effect plays an important role in the solubility, but, as can be seen, salt formation does not influence the propagation of the reaction.

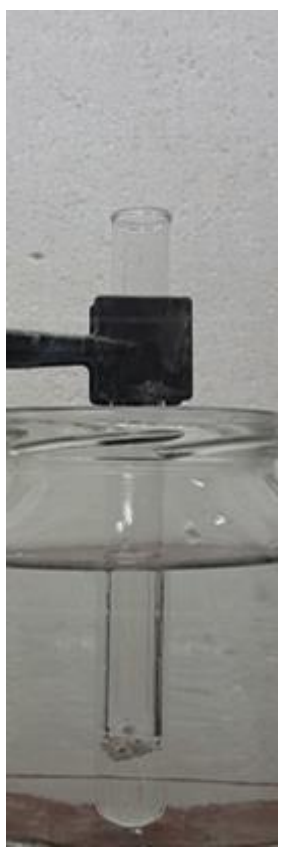

a)

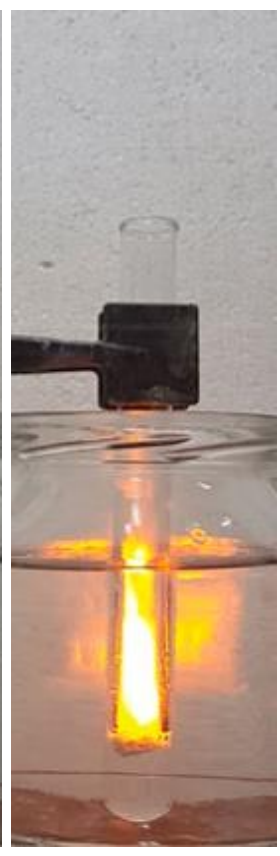

b)

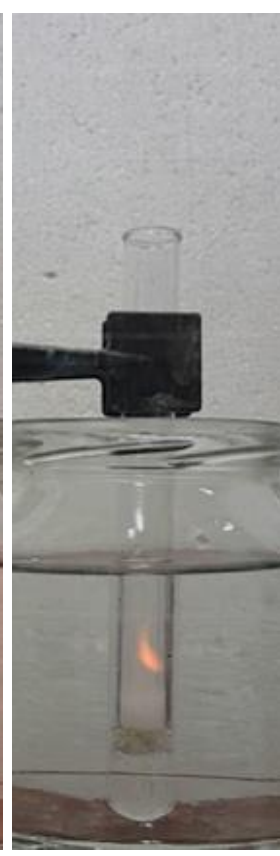

c)

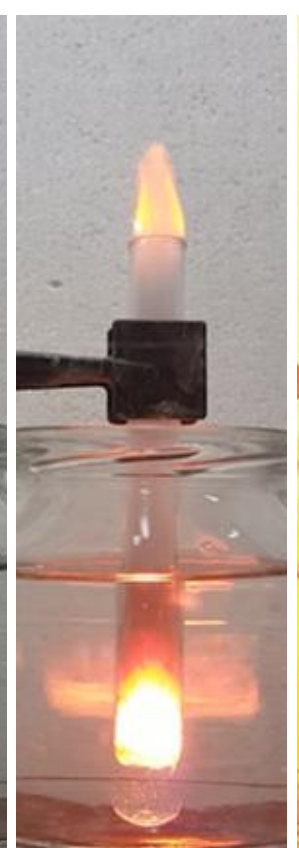

d)

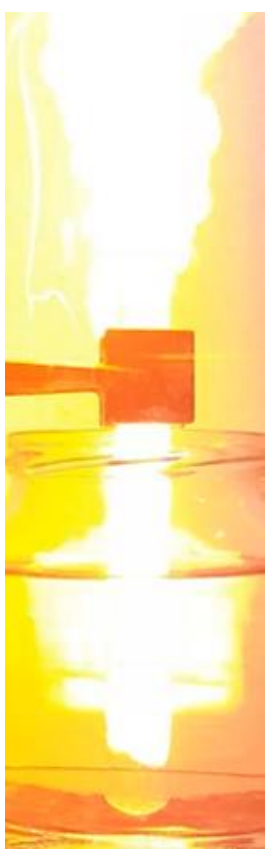

e)

Fig. 12. Reaction of sodium with concentrated sulfuric acid: a) at the moment of contact; b) the released hydrogen ignites after $0.35 \mathrm{~s}$ from the start of the reaction; c) the hydrogen burns but not the metal; d) the metal starts to burn together with the hydrogen; e) an explosion takes place

\subsubsection{Potassium}

When it comes to the reaction of potassium and concentrated sulfuric acid, it is expected without doubt that this reaction should be by far the most vigorous among the reactions of the studied alkali metals. This result is both expected $a$ priori and confirmed experimentally. At the moment of contact the liberated hydrogen ignites spontaneously (Fig. 13a) and after $0.6 \mathrm{~s}$ the metal heats to red heat and ignites (Fig. 13c).

The reactions that take place are the same as for sodium:

$$
\begin{gathered}
2 \mathrm{~K}(\mathrm{~s})+\mathrm{H}_{2} \mathrm{SO}_{4}(\mathrm{l}) \rightarrow \mathrm{K}_{2} \mathrm{SO}_{4}\left(\mathrm{H}_{2} \mathrm{SO}_{4}\right)+\mathrm{H}_{2}(\mathrm{~g}) \\
2 \mathrm{~K}(\mathrm{~s})+2 \mathrm{H}_{2} \mathrm{SO}_{4}(\mathrm{l}) \rightarrow 2 \mathrm{KHSO}_{4}\left(\mathrm{H}_{2} \mathrm{SO}_{4}\right)+\mathrm{H}_{2}(\mathrm{~g})
\end{gathered}
$$




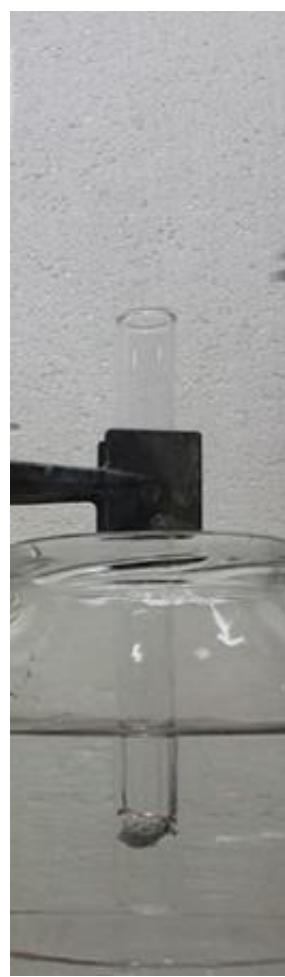

a)

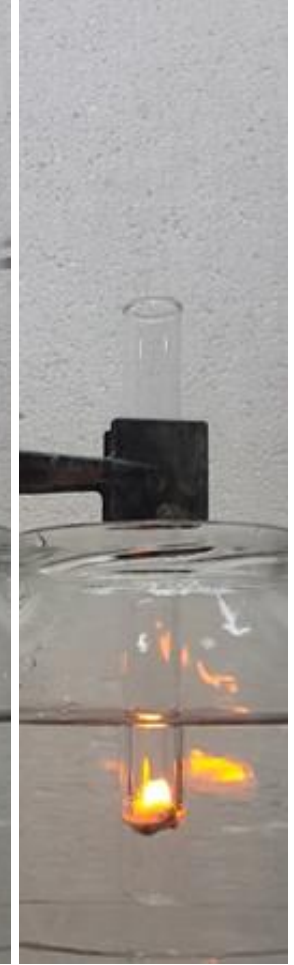

b)

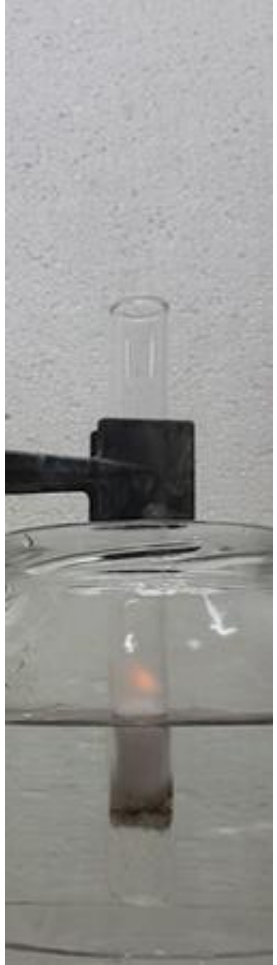

c)

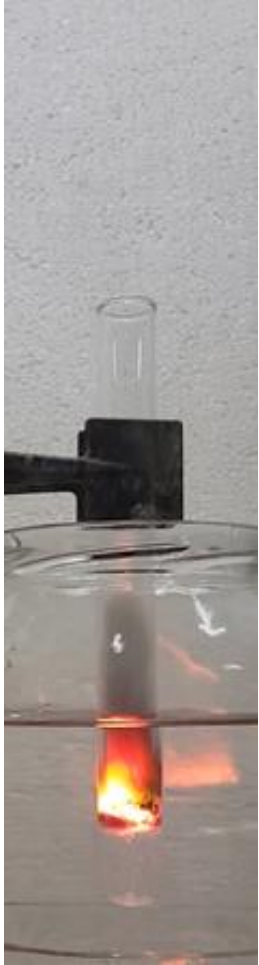

d)

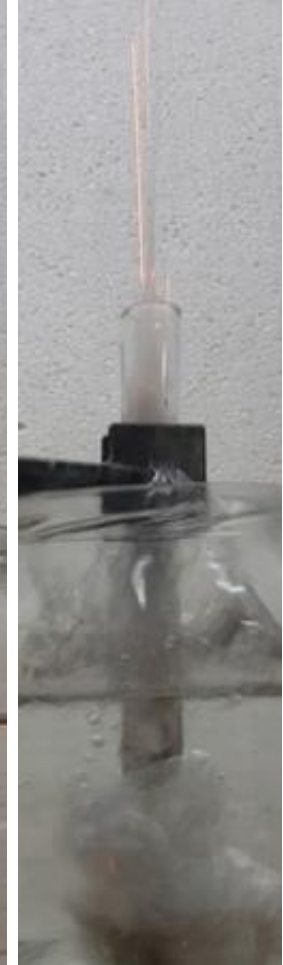

e)

Fig 13. Reaction of potassium with concentrated sulfuric acid: a) at the moment of contact; $\mathbf{b})$ the generated hydrogen ignites, but not the metal; c) the gas burns, but not the metal; d) the metal ignites and the hydrogen continues to burn; e) an explosion occurs.

Potassium sulfate is one of the sulfates with lower solubility. As in the other cases, the commonion effect should further lower that solubility. However, the obtained sulfate reacts with the sulfuric acid and dissolves in the medium. Due to the high concentration a precipitate will form, which is what is observed (Fig. 13c). The literature data [18] suggest that the hydrogen salt can react with sulfuric acid, and other salts can be formed, such as $\mathrm{K}_{3} \mathrm{H}\left(\mathrm{SO}_{4}\right)_{2}$.

\subsection{Reactions with $\mathrm{HClO}_{4}$}

Perchloric acid is the strongest acid used in these experiments. This can be simply concluded from to its $\mathrm{p} K_{\mathrm{a}}$ value (Table 2). Based on this parameter only, one would expect that the most vigorous and highly explosive reactions would be with this acid if the comparison is made with the other acids used in this work. However, it is known that aqueous solutions of up to $70 \%(w / w)$ are not highly oxidizing agents at room temperature. When heated its oxidizing capabilities increase drastically, and solutions of higher concentration $(>72 \%, w / w)$ are really strong oxidizers.

\subsubsection{Lithium}

When taking into consideration the strength of the acid, one could expect that lithium would react more vigorously than with sulfuric acid, since $\mathrm{HClO}_{4}$ is stronger than $\mathrm{H}_{2} \mathrm{SO}_{4}$. However, the actual situation is quite different. The reaction is settled and slow (Fig. 14) with minor amounts of heat being released. In this experiment, for the entire amount of Li to react with the excess of acid, more than 5 min was required.

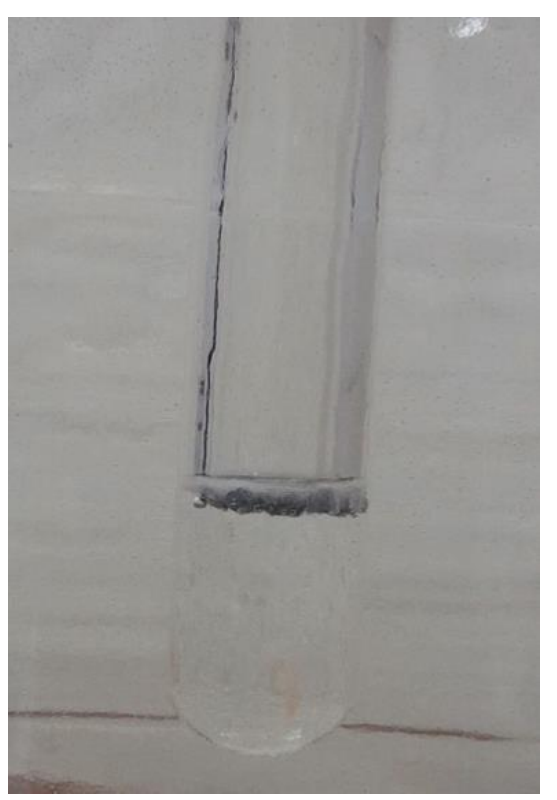

Fig. 14. Relatively slow reaction of lithium with concentrated perchloric acid 
The solubility of lithium perchlorate in water is intermediate (Table 1), so this is not expected to be an obstacle, especially when the outcome of the reaction with potassium is known $\left(\mathrm{KClO}_{4}\right.$ has low solubility). Namely, the commonion effect should have an influence, but it could also affect the reaction with potassium in a similar manner; yet the reaction with potassium is explosive. If a comparison with the reaction of $\mathrm{Li}$ with $\mathrm{H}_{3} \mathrm{PO}_{4}$ is made, it is evident that the rate with $\mathrm{H}_{3} \mathrm{PO}_{4}$ is higher, although $\mathrm{HClO}_{4}$ is a much stronger acid. This comparison is legitimate since the phosphate salts are far less soluble than the perchlorate. The idea of the solubility of the product influencing the rate of the reaction can be ruled out even when the common-ion effect is considered. The only reasonable explanation is that the $\mathrm{HClO}_{4}$ used in these experiments has no pronounced oxidizing properties since its concentration was only $70 \%(w / w)$. The reaction does not generate enough heat, so the acid is not heated enough to become a strong oxidizer and the reaction proceeds slowly.

The chemical equation of the process is simple and can be written as:

$$
2 \mathrm{Li}(\mathrm{s})+2 \mathrm{HClO}_{4}(\mathrm{l}) \rightarrow 2 \mathrm{LiClO}_{4}\left(\mathrm{aq}, \mathrm{HClO}_{4}\right)+\mathrm{H}_{2}(\mathrm{~g})
$$

When water is added to the reaction system, the reaction speeds up, and the piece of lithium is usually ejected out of the test tube or ends up on the inner wall of the test tube (Fig. 15). In this case, the water is added over the lithium, so different parallel reactions take place.

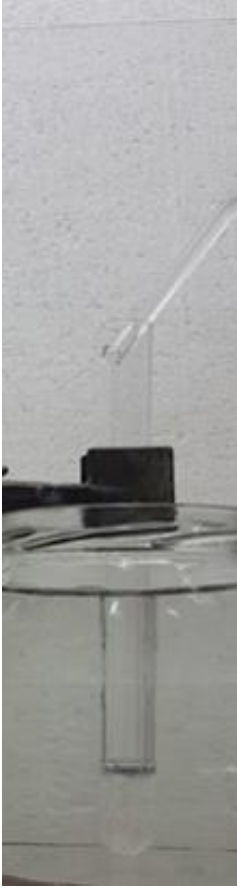

a)

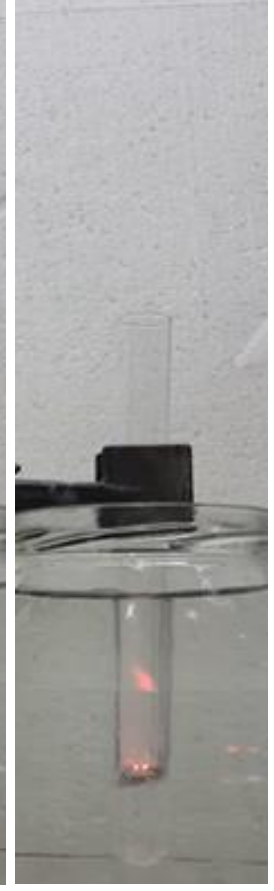

b)

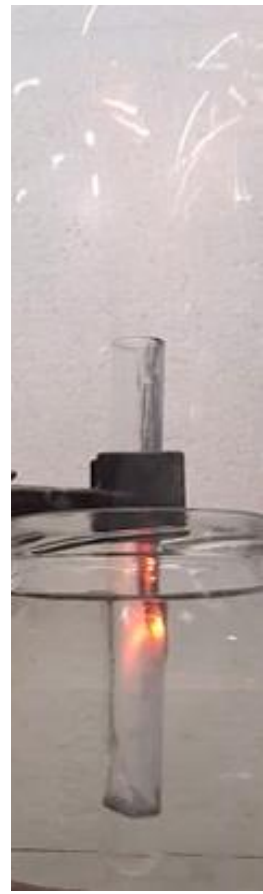

c)
Fig. 15. Addition of water to the lithium-perchloric acid reaction system: a) at the moment of the addition;

b) the reaction speeds up and the generated hydrogen ignites; c) the lithium is ejected

\subsubsection{Sodium}

Unlike the reaction of lithium with $\mathrm{HClO}_{4}$, the reaction of sodium with this acid is in line with expectations. The sodium reacts vigorously with the acid; actually this is the most vigorous reaction of sodium with any of the acids used in this study.

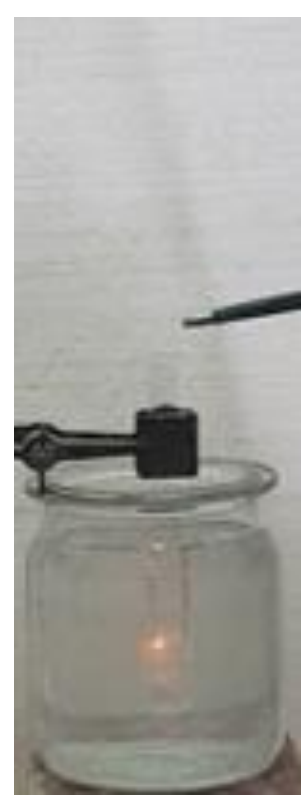

a)

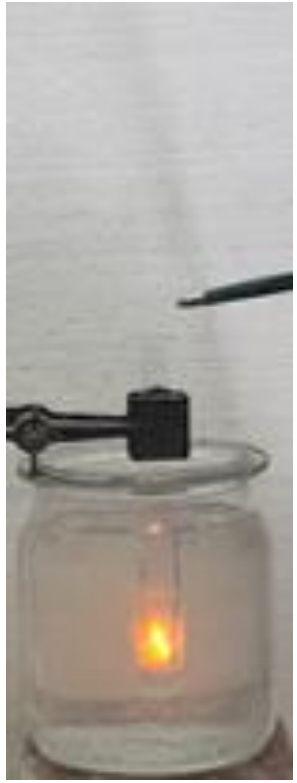

b)

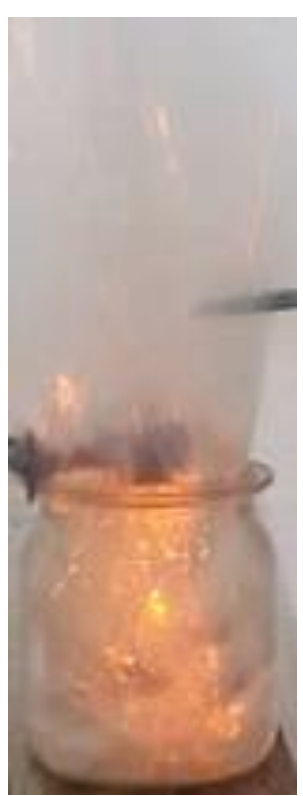

c)

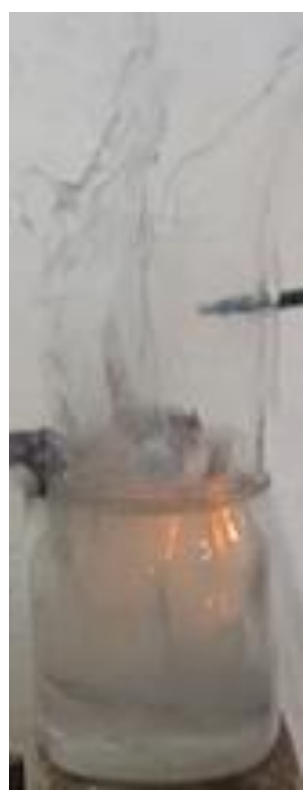

d)

Fig. 16. Reaction of sodium with concentrated perchloric acid: a) at the moment of addition of the metal to the acid; b) the sodium heats up and catches fire; c) and d) explosion 
At the instant when the metal touches the surface of the acid, a gas is generated and the piece of sodium ignites (Fig. 16a). After that, only $0.25 \mathrm{~s}$ is required for an explosion to occur. In this case, the reaction is quite fast and vigorous, so there is not enough time for hydrogen to be generated and ignited. The explosion is rather strong and shatters the test tube, but, in this case, the water acts as medium to partially deflect the shock wave and is ejected from the jar.

The same reaction pattern can be used to write the chemical equation for this process:

$$
2 \mathrm{Na}(\mathrm{s})+2 \mathrm{HClO}_{4}(\mathrm{l}) \rightarrow 2 \mathrm{NaClO}_{4}\left(\mathrm{aq}, \mathrm{HClO}_{4}\right)+\mathrm{H}_{2}(\mathrm{~g})
$$

Sodium perchlorate is very soluble in water, so the common-ion effect will not noticeably influence the speed of the explosive reaction.

\subsubsection{Potassium}

The expected rate and vigorous nature of the reaction with potassium were confirmed by the performed experiment. This can be considered as the most violent reaction of all studied in this work.
At the moment of contact, the hydrogen ignites instantaneously (Fig. 17a) and a huge amount of heat is released. This improves the oxidizing properties of $\mathrm{HClO}_{4}$, so the reaction proceeds at such a rate that explosion becomes inevitable. Interestingly, a moment later the burning of the hydrogen fades and the molten metal heats up (Fig. 17b). After $0.45 \mathrm{~s}$ a very strong explosion takes place.

The reason that the flame is extinguished is probably the result of the obtained product. Potassium perchlorate has a very low solubility in water and the solubility will decrease further due to the common-ion effect. Some of the product surrounds the molten piece of metal, so the released heat is, in a way, localized on the potassium. This, we believe, results in hydrogen production at lower rate, so at a certain point the flame is extinguished. On the other hand, the overheated metal stays encapsulated under the precipitate that is produced continuously and is itself an oxidizing agent. The result is inevitable and a violent explosion takes place. The shockwave spreads very fast, shatters the test tube and is transferred through the water to the glass jar (Fig. 17).

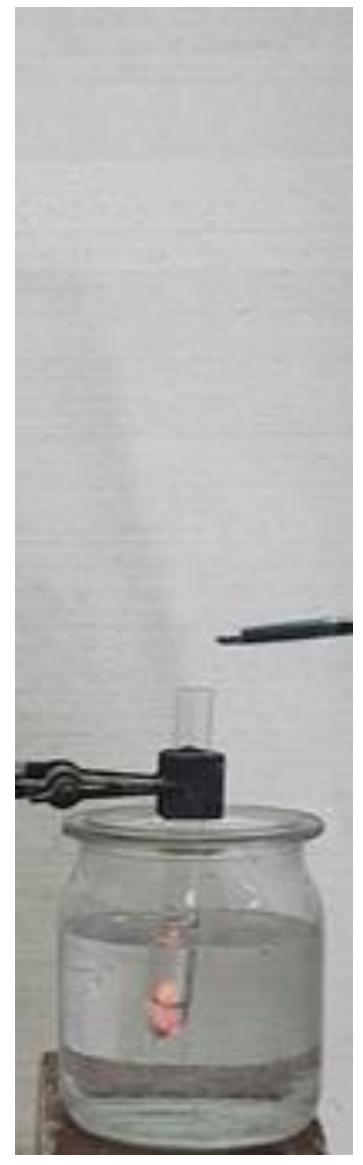

a)

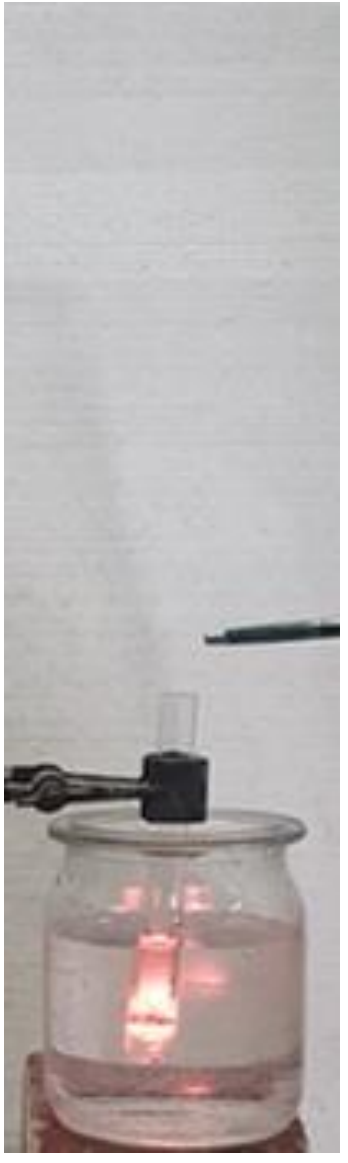

b)

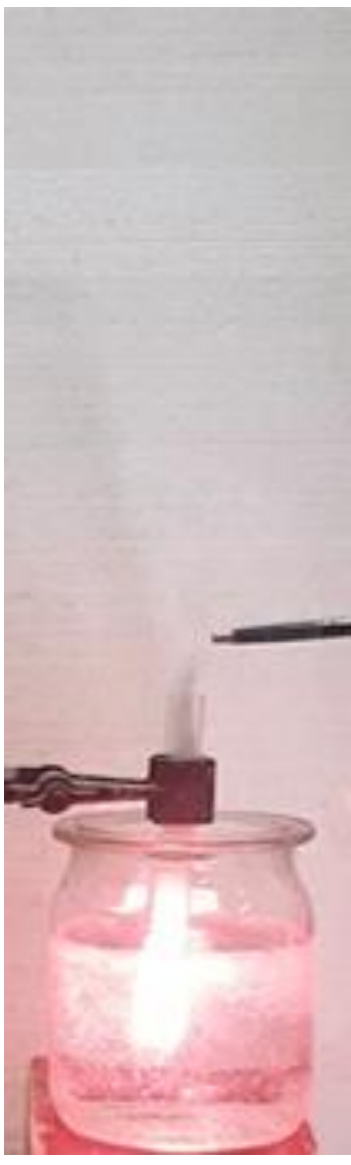

c)

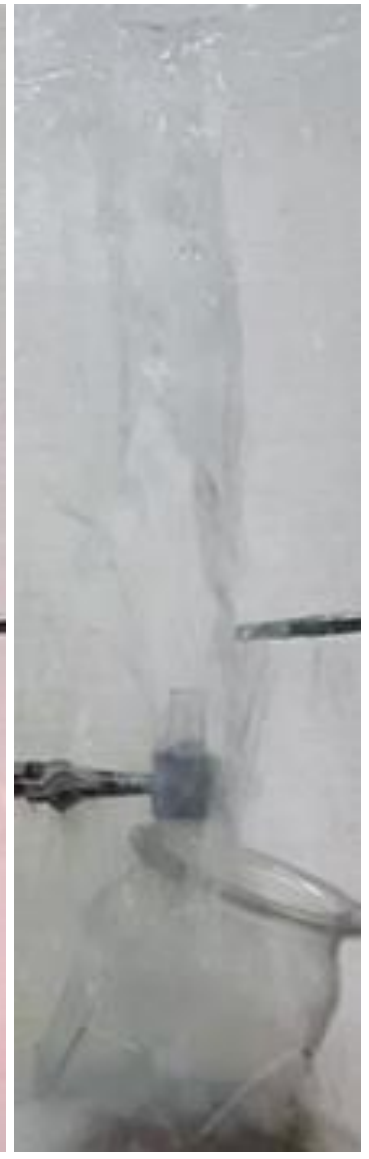

d)

Fig. 17. Reaction of potassium with concentrated perchloric acid: a) at the moment of contact; b) the hydrogen stops burning and the metal heats up; c) and d) a violent explosion occurs 
The glass jar cracks as well, and in this case (due to the strength of the explosion), the water acts as a transfer medium for the shock wave, not as a protector; compare this behavior with that of sodium.

Analogously to the reactions with lithium and sodium, the reaction of potassium with perchloric acid can be expressed by the equation:

$2 \mathrm{~K}(\mathrm{~s})+2 \mathrm{HClO}_{4}(\mathrm{l}) \rightarrow 2 \mathrm{KClO}_{4}\left(\mathrm{aq}, \mathrm{HClO}_{4}\right)+\mathrm{H}_{2}(\mathrm{~g})$

\section{Notes}

Related demonstrations. These reactions can be compared to those of the alkali metals with concentrated hydrohalic acids reported in the recently published article [1]. The assessment can also go further, so one can compare these reactions with those of alkali metals with water [1, 9-19]. All results lead to the conclusion that the reactions with concentrated oxoacids are generally much more vigorous, something that could be expected $a$ priori.

\section{CONCLUSION}

A relatively safe way of performing one of the most dangerous series of demonstration experiments is described. The alkali metals, which are powerful reducing agents, are placed in contact with strong oxidizing agents and these reactions studied systematically up-close. For that purpose $\mathrm{Li}$, $\mathrm{Na}$ and $\mathrm{K}$ are used to reaction with concentrated aqueous solutions of oxoacids: nitric, phosphoric, sulfuric and perchloric acids. Most of the reactions are fast and vigorous, and yet we managed to follow them in great detail. For some of them, rather unusual and unexpected behavior was observed. The reactions were described by chemical equations and their rate and vigorous nature discussed. Suitable explanations supported by the results of the conducted experiments, as well as the available data on the physical and chemical properties, were also offered.

All metals react with the investigated concentrated (aqueous) oxoacids giving the corresponding salts according to the general equations already known. The only observed discrepancy is the reaction of lithium with concentrated nitric and sulfuric acids. Instead of hydrogen, the gas that is generated in large quantities is nitrogen dioxide or sulfur dioxide, respectively, something that is characteristic for metals that are after (below) hydrogen in the electrochemical series of metals. In all other cases, the gas produced during the reaction is hydrogen, which was proven by its ignition in the course of the reaction.
Somewhat unanticipated results concerning the vigorous nature and the rate were observed for the reaction of lithium with perchloric acid. This reaction was unexpectedly slow, even though $\mathrm{HClO}_{4}$ is one of the strongest mineral acids. Namely, the $70 \%(w / w)$ acid has very mild oxidizing properties at room temperature, which is believed to be the reason why the reaction proceeds slowly. On the other hand, the reaction of potassium with $\mathrm{HClO}_{4}$ is explosive and the most vigorous reaction of all those studied. The explanation lies in the fact that during this reaction a large amount of heat is released and at elevated temperatures even the $70 \%$ perchloric acid becomes a very strong oxidizing agent.

All other rates of reactions, as well as their vigorous nature, were according to expectations. The most straightforward conclusions can be drawn about the reactivity of the alkali metals with each acid, without exceptions:

- the reactivity of the alkali metals $(\mathrm{Li}, \mathrm{Na}$, $\mathrm{K})$ increases with their molar mass, so the rate and vigorous nature of the reaction increases as well (this is, admittedly, somewhat trivial).

The other conclusions are not that obvious, and many factors should be considered, such as the nature of the acid, its strength and density, but also its viscosity. Based on these parameters, when the reactions of a given metal were considered, it was concluded that:

- when the density and viscosity of the acids are similar, the rate of reaction increases as the acid strength increases. In this case, the oxidizing property of the acid plays an important role. No matter if the acid is strong, when it is a weak oxidizing agent, the rate of reaction can be unexpectedly low;

-in the case of acids of similar strength, the less viscous liquids show higher reaction rates and of more vigorous nature;

- the less soluble products hinder the concentrated acid in coming into contact with the metal, so the reaction rate decreases as the solubility of the product decreases. The reaction rate is not affected if the product obtained in the first step of the reaction reacts further with the acid to produce a hydrogen or other salt.

The redox reactions of the alkali metals with concentrated oxoacids are interesting enough in themselves, particularly their variation with the nature of the alkali metal. The most interesting ones seem to be the redox reactions of lithium, once again turning the attention of the audience to lithium being quite specific and a member of the set of elements that exhibits diagonal relationships in the Periodic Table. 
For those that are still reluctant to perform this type of demonstration, the available video clip is an absolutely safe alternative. The video clip is educational and at the same time serves as a warning for the students.

\section{SAFETY TIPS AND HAZARDS}

\section{Sodium and potassium metals are highly reactive, and extreme care should be taken when they are used in any experiment! In the presence} of water/acids the metals may spontaneously ignite or even explode. Always wear gloves and a face shield during the preparation of this demonstration. Sodium oxide, sodium peroxide, potassium peroxide, potassium superoxide, sodium hydroxide and potassium hydroxide (the first four are products of burning sodium/potassium in air; the latter are formed in the reaction of sodium/potassium with water) are caustic and skin and eye irritants. All remaining pieces of metal and spills should be carefully collected and destroyed by tap water or ethanol (for the more conservative experimenter) in a glass beaker.

All oxoacids considered and used in this work are strong inorganic acids and are highly corrosive materials due to their oxidative strength. They cause severe damage to tissues. Always wear gloves and a face shield during the preparation of these experiments and their handling. If they come in contact with the skin, dry the affected area with paper towel and then wash it with copious running tap water for at least 5 minutes. Afterwards, treat the area with a $5 \%$ solution of baking soda $\left(\mathrm{NaHCO}_{3}\right)$. Chemical spills should be treated with excess solid $\mathrm{NaHCO}_{3}$ and washed with copius quantities of water.

We advise the reader to check on the safety tips in our earlier contribution [1].

Supporting material. All video clips and pictures for the performed experiments were made using a Canon EOS 100D camera and are available as supporting material. Figures 3-17 are snapshots from the video clips and are given under the corresponding names in the collection of videos under the general name M_HxAOy.mp4.

Li_HNO $3 . m p 4$ - reaction of lithium with concentrated nitric acid

Na_HNO $3 . m p 4$ - reaction of sodium with concentrated nitric acid

$\mathrm{K} \_\mathrm{HNO}_{3} . \mathrm{mp} 4$ - reaction of potassium with concentrated nitric acid

$\mathrm{Li}_{-} \mathrm{H}_{3} \mathrm{PO}_{4} \cdot \mathrm{mp} 4$ - reaction of lithium with concentrated phosphoric acid

$\mathrm{Na}_{-} \mathrm{H}_{3} \mathrm{PO}_{4}$.mp4 - reaction of sodium with concentrated phosphoric acid

$\mathrm{K} \_\mathrm{H}_{3} \mathrm{PO}_{4} \cdot \mathrm{mp} 4$ - reaction of potassium with concentrated phosphoric acid

$\mathrm{Li}_{-} \mathrm{H}_{2} \mathrm{SO}_{4} . \mathrm{mp} 4$ - reaction of lithium with concentrated sulfu- ric acid

$\mathrm{Na} \_\mathrm{H}_{2} \mathrm{SO}_{4} . \mathrm{mp} 4$ - reaction of sodium with concentrated sulfuric acid

K_ $\mathrm{H}_{2} \mathrm{SO}_{4}$.mp4 - reaction of potassium with concentrated sulfuric acid

Li_HClO4.mp4 - reaction of lithium with concentrated perchloric acid

$\mathrm{Na} \_\mathrm{HClO}_{4} . \mathrm{mp} 4$ - reaction of sodium with concentrated perchloric acid

$\mathrm{K}_{-} \mathrm{HClO}_{4}$.mp4 - reaction of potassium with concentrated perchloric acid

\section{REFERENCES}

[1] S. Aleksova, M. Bukleski, V. M. Petruševski, A Safe Way of Performing Dangerous Experiments. III. The Safety Box. 1. Demonstrating the Reactions of Alkali Metals with Concentrated Acids of the Type HX(aq) (X $=\mathrm{F}, \mathrm{Cl}, \mathrm{Br}, \mathrm{I})$, Maced. J. Chem. Chem. Eng. 37 (1), 8998 (2018). DOI: 10.20450/mjcce.2017.1424

[2] V. M. Petruševski, M. Ž. Najdoski, A safe way of performing some dangerous experiments. I. Construction of a safety spoon, Chem. Educator, 7, 81-83 (2002). DOI: $10.1007 / \mathrm{s} 00897020546 \mathrm{a}$

[3] V. M. Petruševski, M. Ž. Najdoski, A safe way of performing some dangerous experiments. II. Construction of a safety dropper, Chem. Educator, 7, 220-222 (2002). DOI: $10.1007 / \mathrm{s} 00897020583 \mathrm{a}$.

[4] Metals in concentrated acid and water, https://www.youtube.com/watch?v=BAX8P36dV0g (last accessed 03.04.2020).

[5] Sodium metal reacting with concentrated hydrochloric acid, https://www.youtube.com/watch?v=CXDhdVMKKF4 (last accessed 03.04.2020).

[6] Lithium metal reacting with concentrated hydrochloric acid, https://www.youtube.com/watch?v=3bVVVCblPVY (last accessed 03.04.2019).

[7] Potassium metal reacting with concentrated hydrochloric acid,

https://www.youtube.com/watch?v=53T5WZHQ_Ck (accessed 03.04.2020).

[8] Sodium reacts with four acids, https://www.youtube.com/watch?v=qZxW1QKdLq8 (accessed 03.04.2020).

[9] M. Dale Alexander, Reactions of the alkali metals with water: a novel demonstration, J. Chem. Educ. 69, 418419 (1992). DOI: 10.1021/ed069p418

[10] N. Stavrevska, V. M. Petruševski, V. Ivanovski, Reaction of sodium with water vapor - a short marathon experiment with somewhat unexpected result, Chem. Educator, 15, 321-324 (2010). DOI: 10.1333/s00897102294a

[11] Alkali metals reacting with water, https://www.youtube.com/watch?v=jI_JY7pqOM (last accessed 03.04.2020).

[12] Sodium and water, http://www.pc.chemie.uni-siegen.de/ $\mathrm{pci} / \mathrm{versuche/english/v44-1-1.html}$ (last accessed 03.04.2020).

[13] Sodium in water chemistry demonstration, https://www. thoughtco.com/sodium-in-water-chemistry -demonstration-604254 (last accessed 03.04.2018). 
[14] Potassium in water (reaction only), https://www.youtube.com/watch?v=Jy1DC6Euqj4 (last accessed 03.04.2020).

[15] Safe video demonstration sodium and potassium exploding in water, http://www.instructables.com/id/Sodiumand-Potassium-In-Water/ (last accessed 03.04.2020).

[16] Mitch Jacoby, Why sodium and potassium really explode in Water, https://cen.acs.org/articles/93/web/2015/01/SodiumPotassium-Really-Explode-Water.html (last accessed 03.04.2020).

[17] M. Bukleski, V. Ivanovski, V. M. Petruševski, IR specular reflectance spectra of $\mathrm{KHSO}_{4}$ single crystal - Dispersion analysis, Vib. Spectrosc. 57, 15-22 (2011). DOI: 10.1016/j.vibspec.2011.04.003

[18] Y. Noda, S. Uchiyama, K. Kafuku, H. Kasatani, H. Terauchi, Structure Analysis and Hydrogen Bond Character of $\mathrm{K}_{3} \mathrm{H}\left(\mathrm{SO}_{4}\right)_{2}$, J. Phys. Soc. Jpn. 59, 2804-2810 (1990). DOI: 10.1143/JPSJ.59.2804

[19] CRC Handbook of Chemistry and Physics, 97 $7^{\text {th }}$ ed., W.M. Haynes, CRC Press Taylor and Francis Group, Boca Raton, FL, 2017.

[20] Properties of lithium, and the reactions of water and certain acids with lithium, https://melscience.com/US en/articles/properties-lithium-and-reactions-water-andcertain/ (last accessed 11.12.2020).

[21] Lithium react with nitric acid, https://chemiday.com/en/reaction/3-1-0-7011 (last accessed 11.12.2020).

[22] P. E. Mason, F. Uhlig, V. Vaněk, T. Buttersack, S. Bauerecker, P. Jungwirth, Coulomb explosion during the early stages of the reaction of alkali metals with water, Nat. Chem., 7, 250-254 (2015).

DOI: $10.1038 / \mathrm{nchem} .2161$
[23] V. M. Petruševski, M. Bukleski, On the Coulomb explosion during the reaction of alkali metals with water, in preparation.

[24] N. N. Greenwood, A. Earnshaw, Chemistry of the Elements, $2^{\text {nd }}$ ed., Oxford, Butterworth-Heinemann, 1997. DOI: 10.1016/C2009-0-30414-6.

[25] G. Rayner-Canham, Isodiagonality in the Periodic Table, Found Chem. 13, 121-129 (2011). DOI: $10.1007 / \mathrm{s} 10698-011-9108-y$

[26] Compound summary Nitric acid, https://pubchem.ncbi.nlm.nih.gov/compound/nitric_acid (last accessed 11.12.2020).

[27] O. T. Fasullo, Sulfuric Acid: Use and Handling, McGraw-Hill, St. Louis 1965, p. 304

[28] O. W. Edwards, E. O. Huffman, Viscosity of aqueous solutions of phosphoric acid at $25^{\circ} \mathrm{C}, \mathrm{J}$. Chem. Eng. Data, 3, 145-146 (1958). DOI: 10.1021/1460003a028

[29] L. H. Brickwedde, Properties of aqueous solutions of perchloric acid, J. Res. Natl. Inst. Stan. 42, 309-329 (1949).

[30] Steffen's Chemistry Pages, Density of phosphoric acid, https://wissen.science-and-fun.de/chemistry/chemistry/ density-tables/density-of-phosphoric-acid/, (last accessed 11.12.2020).

[31] T. G. Hiss, E. L. Cussler, Diffusion in high viscosity liquids, AIChE J. 19, 698-703 (1975). DOI: 10.1002/aic.690190404.

[32] E. Kemnitz, C. Werner, H. Worzala, S. Trojanov, Y. T. Strutschkov, Ein neues Lithiumhydrogensulfat, $\mathrm{Li}_{2}\left(\mathrm{HSO}_{4}\right)_{2}\left(\mathrm{H}_{2} \mathrm{SO}_{4}\right)$ - Synthese und Kristallstruktur, $Z$. Anorg. Allg. Chem. 621, 675-678 (1995). DOI: $10.1002 /$ zaac. 19956210728 